University of Arkansas, Fayetteville

ScholarWorks@UARK

Graduate Theses and Dissertations

8-2018

\title{
Quantifying Carbon Dioxide Fluxes in the Air and Water in Blowing Springs Cave, Arkansas
}

Holly Young

University of Arkansas, Fayetteville

Follow this and additional works at: https://scholarworks.uark.edu/etd

Part of the Geology Commons, and the Hydrology Commons

\section{Citation}

Young, H. (2018). Quantifying Carbon Dioxide Fluxes in the Air and Water in Blowing Springs Cave, Arkansas. Graduate Theses and Dissertations Retrieved from https://scholarworks.uark.edu/etd/2844

This Thesis is brought to you for free and open access by ScholarWorks@UARK. It has been accepted for inclusion in Graduate Theses and Dissertations by an authorized administrator of ScholarWorks@UARK. For more information, please contact scholar@uark.edu. 
Quantifying Carbon Dioxide Fluxes in the Air and Water in Blowing Springs Cave, Arkansas

\begin{abstract}
A thesis submitted in partial fulfillment of the requirements for the degree of Master of Science in Geology
\end{abstract}

by

\author{
Holly Young \\ University of Arkansas
}

Bachelor of Science in Geology, 2015

August 2018

University of Arkansas

This thesis is approved for recommendation to the Graduate Council.

Matthew Covington, $\mathrm{PhD}$

Thesis Director

Ralph Davis, PhD

Committee Member
Celina Suarez, $\mathrm{PhD}$

Committee Member 


\begin{abstract}
Prior work has shown that the concentration of carbon dioxide $\left(\mathrm{CO}_{2}\right)$ within cave atmospheres is a function of cave airflow patterns. The dynamics of $\mathrm{CO}_{2}$ within karst systems are of increasing interest as they can control periods of precipitation or dissolution in speleothems and influence potential interpretations of paleoclimate records. Similarly, $\mathrm{CO}_{2}$ is an important driver of speleogenesis, and air-water $\mathrm{CO}_{2}$ dynamics can control patterns of cave passage evolution. Karst also plays an uncertain role in the global carbon cycle and understanding $\mathrm{CO}_{2}$ dynamics within karst systems will aid the development of carbon budgets. Here, a monitoring station was deployed to study the temporal variations of dissolved and gaseous $\mathrm{CO}_{2}$ concentrations in Blowing Springs Cave in Bella Vista, Arkansas. Results show fluctuations in $\mathrm{CO}_{2}$ concentrations are controlled by density driven chimney effect airflow. The chimney effect is driven by outside temperature changes, which influence the relative density of cave air and outside air. During the winter months, air is pulled into the lower, main entrance resulting in low $\mathrm{CO}_{2}$ concentrations within the cave. During the summer months, $\mathrm{cool} \mathrm{CO}_{2}$ rich cave air from the cave flows out the entrance and $\mathrm{CO}_{2}$ levels in the cave rise. The $\mathrm{CO}_{2}$ concentration in the air is immediately affected by the reversals in airflow. However, in the water delayed responses were observed to changes in airflow direction. Airflow velocity and discharge are also being measured, so that $\mathrm{CO}_{2}$ fluxes within both the air and water can be quantified. Longitudinal profiles of gaseous and dissolved $\mathrm{CO}_{2}$ within the cave were constructed from spot measurements of $\mathrm{CO}_{2}$ during different seasons and airflow regimes. Ultimately, the observations are used to quantify $\mathrm{CO}_{2}$ fluxes, to examine the diurnal and seasonal changes in gaseous and dissolved $\mathrm{CO}_{2}$ and to quantify interactions between the air and water.
\end{abstract}




\section{Acknowledgements}

I want to extend my sincere gratitude to my advisor, Dr. Matthew Covington, for first taking me into his research group as an undergrad with enthusiasm for karst studies, envisioning this project and support every step of the way. This research could not have been completed without your advice, ideas and enthusiasm. I would also like to thank the rest of my committee members, Dr. Celina Suarez and Dr. Ralph Davis for your reviews and support for this thesis. Outside of my committee, I also want to thank Dr. Van Brahana for always showing enthusiasm for my research and for igniting my enthusiasm for karst.

I would also want to thank Dr. Covington's research group member throughout my time at the University. First, to Kathy Knierim, whose enthusiasm for Blowing Springs Cave and graciously supplying data and maps of Blowing Springs helped tremendously in the first years of my research. Second, to Josue Rodriguez who helped solve many problems I came across and joining in to do the grunt work collecting the data. Third, to the rest of the research group for providing ideas in and outside group meeting. Finally, to the numbers of friends and colleagues who enthusiastically and sometimes reluctantly joined my monthly (or more) trips to Blowing Springs. You made my research exciting and gave me many memories, some miserable, but most worth keeping.

I would like to thank my parents for, Libby and Robert Young, and my sister, Morgan Young, for your encouragement, support and your consistent push to complete my research. I also would like to thank the rest of my family and friends who have supported my through my graduate years. Thank you, Dustin Baucom, for pushing me through the last year of my research and helping along the way. 
Last but certainly not least, I would also like to thank the Department of Geosciences. I am so grateful for my time here as a student. I've had wonderful experiences with all the professors, staff and students who I have grown fond of. The community within the department is one near family. I have countless memories here that are priceless. 


\section{Table of Contents}

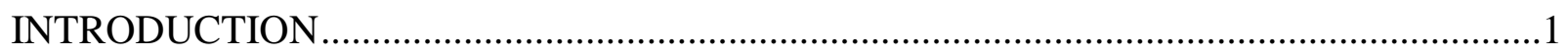

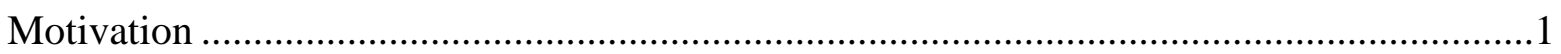

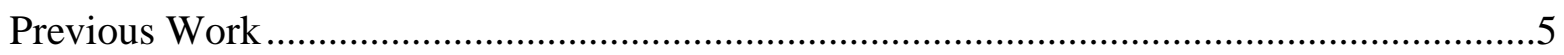

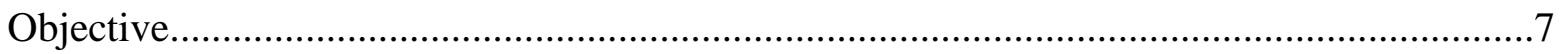

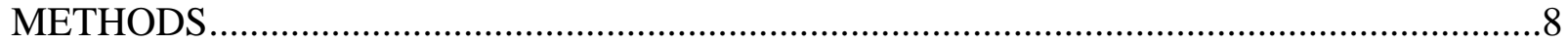

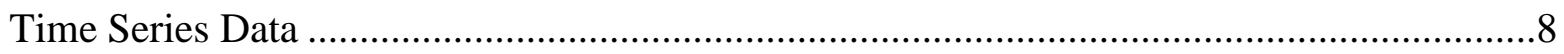

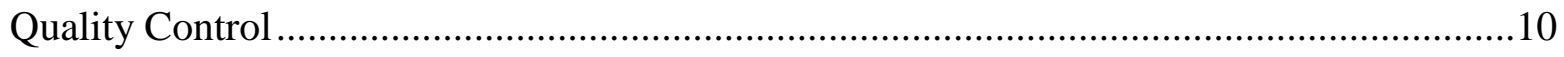

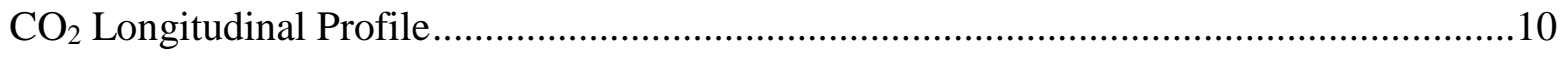

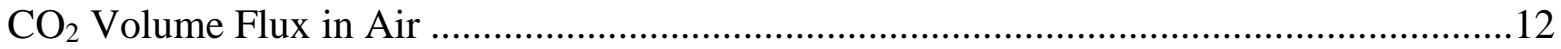

Calculating Stream Discharge ............................................................................. 13

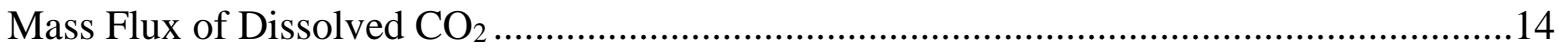

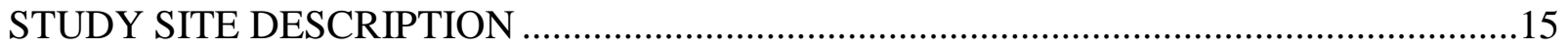

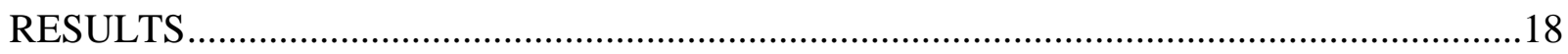

Airflow Patterns....................................................................................................... 21

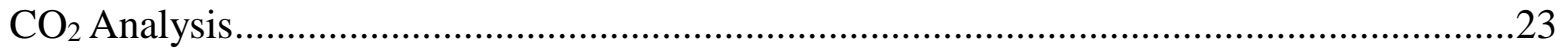

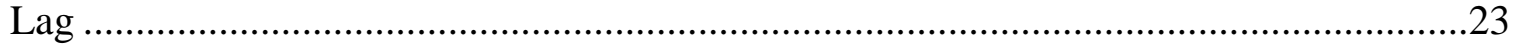

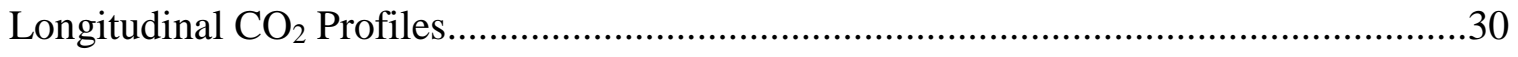

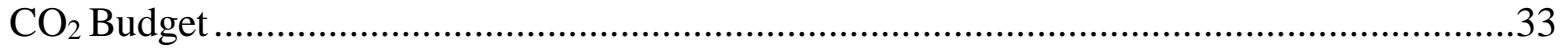

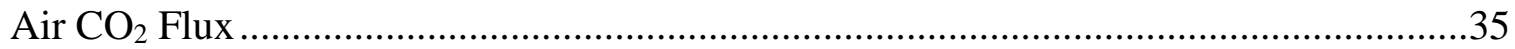


Water $\mathrm{CO}_{2}$ Flux

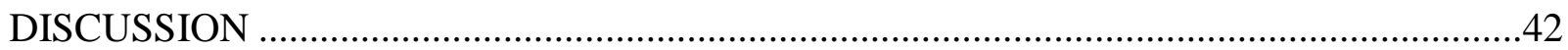

The Chimney Effect ................................................................................................ 42

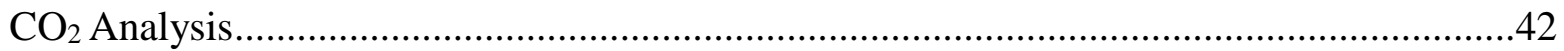

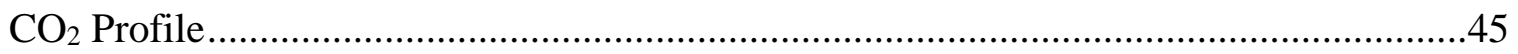

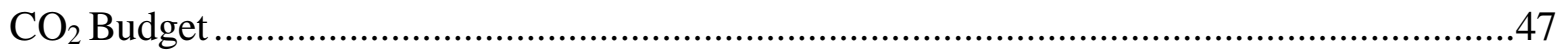

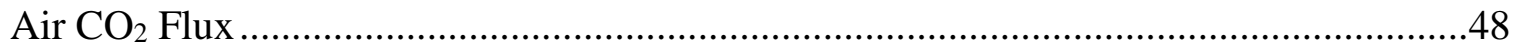

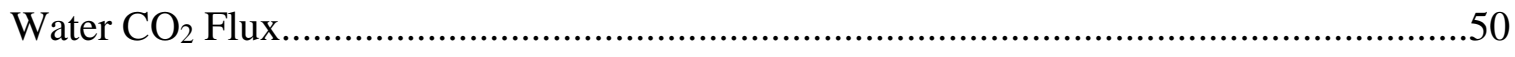

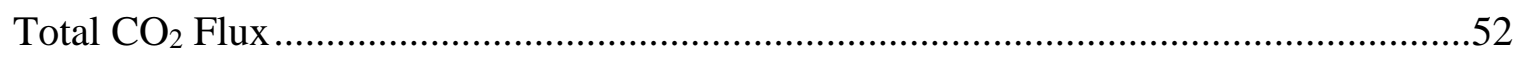

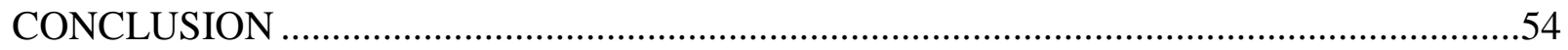

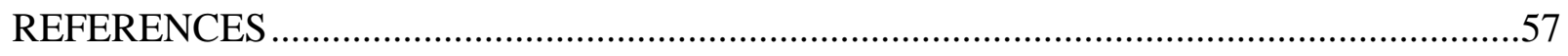




\section{INTRODUCTION}

\section{Motivation}

In karst environments, carbon dioxide $\left(\mathrm{CO}_{2}\right)$ is a dominant control in the process of carbonate dissolution and precipitation (Dreybrodt, 1999). When $\mathrm{CO}_{2}$ dissolves in water $\left(\mathrm{H}_{2} \mathrm{O}\right)$ it produces carbonic acid. When this acidic solution enters a karst system it reacts with the carbonate rock to dissolve calcite $\left(\mathrm{CaCO}_{3}\right)$ and release calcium $\left(\mathrm{Ca}^{2+}\right)$ and bicarbonate $\left(\mathrm{HCO}_{3}{ }^{-}\right)$ ions into the solution (Dreybrodt, 1996).

$$
\mathrm{CaCO}_{3}+\mathrm{CO}_{2}+\mathrm{H}_{2} \mathrm{O} \leftrightarrow \mathrm{Ca}+2 \mathrm{HCO}_{3}
$$

The more $\mathrm{CO}_{2}$ is introduced into the system, the more carbonic acid is produced, which increases the dissolution rate of calcite and the growth rate of karst cavities. A decrease in $\mathrm{CO}_{2}$ concentrations within a karst system can result in speleothem growth through precipitation of calcite.

The dynamics of carbon dioxide $\left(\mathrm{CO}_{2}\right)$ within karst systems are of increasing interest as they can control periods of precipitation or dissolution in speleothems. Knowing $\mathrm{CO}_{2}$ is the leading source of dissolution in karstic waters, and air-water $\mathrm{CO}_{2}$ dynamics can control patterns of cave passage evolution, it is important to understand the factors affecting these changes in concentration. Karst atmospheres contain, on average, higher concentrations of $\mathrm{CO}_{2}$ than at the surface (Pla et al. 2016). Although there have been many studies of $\mathrm{CO}_{2}$ concentrations in cave air and water (Cigna, 1968; Dreybrodt, 1999; Spo“tl et al., 2005; Baldini et al., 2006; Bourges et al., 2006; Johnson et al., 2009; Milanolo and Gabrosvek, 2009; Cowan et al., 2011; Yan et al., 2011; Breecker et al., 2012; Sánchez-Cañete et al., 2013; Gulley et al., 2014; Pu et al., 2014; Covington, 2015; Covington \& Perne, 2015; Knierim, 2015; Knierim et al., 2015; Lang et al., 
2015; Vaughn, 2015; Holcomb, 2016; Mattey et al., 2016; Pla et al., 2016; Houillon et al., 2017), there have been few studies that have collected long-term high temporal resolution $\mathrm{CO}_{2}$ data, particularly of dissolved $\mathrm{CO}_{2}$ concentrations (Vaughn, 2015; Holcomb, 2016). Potential sources of $\mathrm{CO}_{2}$ within karst systems include microbial decay of organic matter, $\mathrm{CO}_{2}$ transport by tectonic or volcanic activity, and anthropogenic fluxes (Lang et al., 2015). Most $\mathrm{CO}_{2}$ transport within cave systems occurs via cave ventilation or by stream flow. Within larger cave passages transport of carbon dioxide through advection is likely to be dominant (Covington, 2015).

(a)

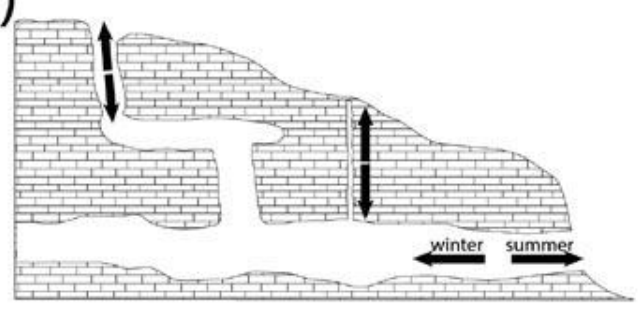

(b)

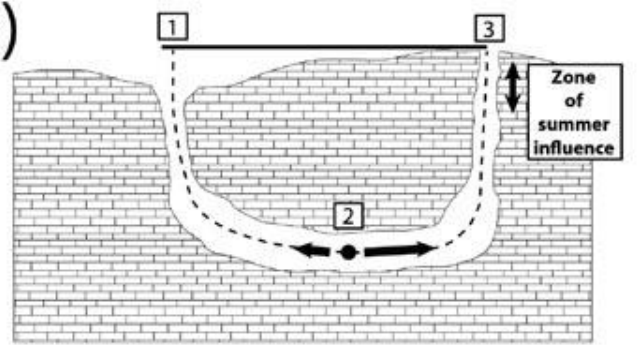

(c)

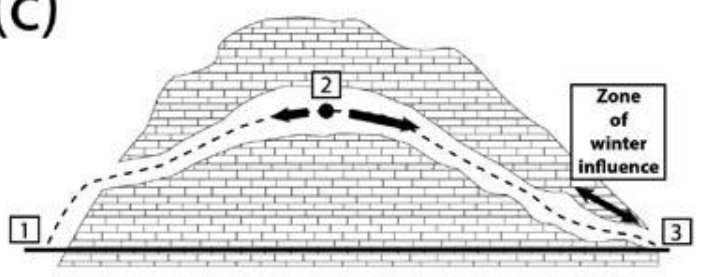

(d)

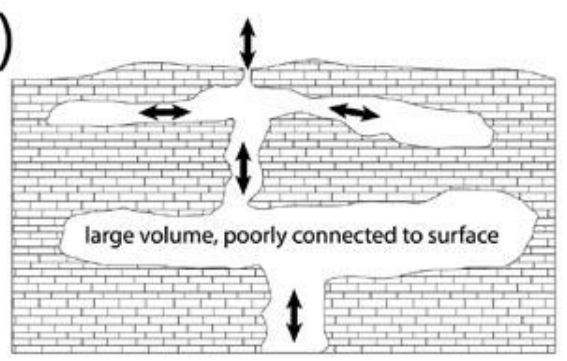

(e)

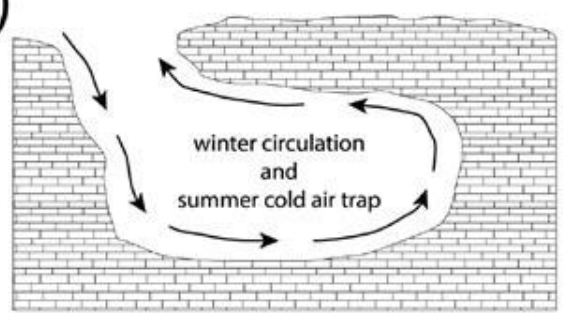

(f)

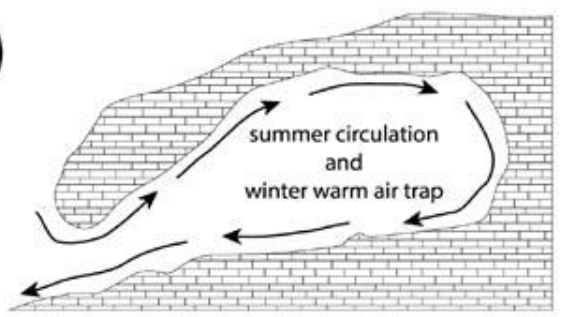

Figure 1: Mechanisms for cave airflow. Temperature driven airflow shown in a), b), c), e) andf). Chimney effect airflow, a) occurs in caves with different entrances/flow paths at different elevations. Depending on the cave geomentry chimney effect flows may be stronger in the summer $b$ ) or winter $c$ ). In temperature driven caves with only one entrance the cave can be circulating in the winter e) or summer f) depending on their geometries. Barometric pressure driven airflow can be a dominant airflow mechanism where the geometry of the cave has large volumes and poorly connected to the surface. (Covington \& Perne, 2015) 
The concentration of $\mathrm{CO}_{2}$ within cave atmospheres is a strong function of cave airflow patterns. Many authors previously have observed cave ventilation as a controlling factor in carbon dioxide migration and exchange in caves around the world (Spo“tl et al., 2005; Milanolo, 2009; Breeker et al., 2012; Cowan et al., 2013). A variety of cave ventilation mechanisms have been observed including: chimney effect airflow, circulating convective airflow, barometric airflow, water entrainment airflow, airflow due to changes in air volume from floodwaters, and surface wind driven airflow (Figure 1) (Cigna, 1968; Wigley \& Brown, 1976; Covington \& Perne, 2015).

The most common airflow mechanism is the chimney effect, which occurs in caves with multiple entrances for airflow to enter and escape from. Covington and Perne (2015) explore the nature of this airflow regime where air will flow in and out entrances of varying elevations. The chimney effect is density driven by temperature differences between the internal and external air. Air will flow between the upper and lower entrances instead of being circulated within the cave (Wigley and Brown, 1976; Spötl et al., 2005; Covington \& Perne, 2015). During the winter months, dense outside air is pulled into a lower entrance and lighter cave air is pushed out the upper entrance, circulating external air throughout the cave. Typically, in this case, $\mathrm{CO}_{2}$ levels reach a low value near atmospheric concentrations. During the summer months, cool dense cave air sinks and flows out a lower entrance, pulling lighter atmospheric air into the upper entrance (Covington \& Perne, 2015). Since this air often passes through the high $\mathrm{CO}_{2}$ soil zone before entering the cave $\mathrm{CO}_{2}$ concentrations in a cave often rise under warm conditions.

Caves with one large entrance for airflow to circulate, experience an airflow pattern called the circulating convection airflow regime. This airflow regime occurs when a large entrance can hold airflow moving in and out simultaneously (Covington \& Perne, 2015). Like 
the chimney effect, the circulating convection airflow is also temperature driven. If the cave sits below the entrance, air is circulated during the colder months, as dense external air falls through the entrance pushing the lighter cave air out the entrance (Covington \& Perne, 2015). If the cave sits above the entrance, air is circulated during the warmer months, as denser cave air falls, pushing the cave air out the entrance and pulling the lighter external air into the entrance (Covington \& Perne, 2015). The circulating airflow will help to reduce the difference between the external temperatures and the cave rock temperatures. As circulation becomes consistent over time, the circulation may shut off if the cave rock temperatures equilibrate with the external temperatures (Covington \& Perne, 2015).

Another cave airflow system is driven by barometric pressure changes called the barometric airflow regime. This type of airflow regime are characteristic in caves with large cavities with little connectivity to the surface such as hypogene cave systems, or caves that were formed from water rising to the surface (Covington \& Perne, 2015).

Within any wet cave $\mathrm{CO}_{2}$ gas will transfer between the air and the water. This gas transfer is driven by the differences in $\mathrm{CO}_{2}$ partial pressures in the air and water. Stream gradients and hydraulics play a significant role in determining gas transfer velocities (Jähne and Haußecker, 1998; Wanninkhof et al., 2009; Covington et al., 2013). The $\mathrm{CO}_{2}$ gas transfer influences when precipitation or dissolution is occurring in a cave. Understanding the $\mathrm{CO}_{2}$ exchange between cave air and water is of increasing importance as its controls are discovered on the rate and patterns of cave passage evolution. 


\section{Previous Work}

Karst plays an uncertain role in the global carbon cycle (Pu et al., 2014). Understanding $\mathrm{CO}_{2}$ dynamics within karst systems will aid the development of global carbon budgets.

Therefore, an increasing amount of work has focused on $\mathrm{CO}_{2}$ dynamics in differing karst settings with a variety of potential driving forces. In a study by Mattey (2016) a model visualized the relationship of carbon cycling through the air, water and soil.

Previous studies have observed the $\mathrm{CO}_{2}$ gas exchange between air and water columns in large streams, dripwater, and condensation of cavity walls. Houillon (2017) observed the $\mathrm{CO}_{2}$ dynamics within the exfiltration and condensation waters in a highly ventilated adorned cave in Spain. To estimate the potential danger to the cave drawings, Houillon (2017) determined the relationships between the partial pressures in the air and both condensation and exfiltration waters with three equations. They determined the condensation water has dissolution potential, while the exfiltration water is constantly supersaturated and will only have the potential to precipitate. When the air $\mathrm{pCO}_{2}$ is high, the condensation on the walls lead to dissolution. In the exfiltration water, precipitation will occur when there is a sufficient difference between the $\mathrm{PCO}_{2}$ of the air and the $\mathrm{pCO}_{2}$ of the exfiltration water. Understanding the $\mathrm{CO}_{2}$ dynamics within this cave, determined the route cave management should take (Houillon et al., 2017).

A study by Spötl (2005) in Obir Caves in Austria, observes how cave air ventilation is the driving factor in dripwater geochemistry. Monthly samples of cave air and water were taken to measure $\mathrm{CO}_{2}$, and then they calculated water $\mathrm{pCO}_{2}$ using PHREEQC. $\mathrm{CO}_{2}$ in the air followed a trend that could be explained by ventilation. In periods of high ventilation, $\mathrm{CO}_{2}$ in the air reached a low, and during low ventilation $\mathrm{CO}_{2}$ in the air was high. The trend was also mirrored in the calculated water $\mathrm{pCO}_{2}$ with degassing occurring during high ventilation. Due to the ventilation in 
the cave air, the chemistry of the cave water was changed, controlling cave dissolution or precipitation.

A study in an eogenetic Florida cave by Gulley (2014), discovered ventilated air-water $\mathrm{CO}_{2}$ dynamics drives dissolution in this cave, rather than the most widely cited mechanism seen in eogenetic caves, mixing dissolution. They used high-resolution 1-year timeseries of specific conductivity, temperature, meteorological data, and spot water chemistry measurements. They found when the cave experiences little ventilation (high air $\mathrm{CO}_{2}$ ) dissolution increased, and in periods of high ventilation (low air $\mathrm{CO}_{2}$ ) potential dissolution decreased. Changes in $\mathrm{pCO}_{2}$ of less than $1 \%$ in the air along flow paths are much more efficient in producing dissolution than mixing of vadose and phreatic water (Gulley et al., 2014)

Some caves experience density driven airflow patterns controlled by cave geometry and changing external temperatures. The ventilation patterns are reflected in the concentrations of $\mathrm{CO}_{2}$ in the air. A cave in Bosnia and Herzegovina reflected two advective ventilation patterns with only one airflow entrance, causing temporal variations of $\mathrm{CO}_{2}$ concentrations. Milanolo and Gabrosvek (2009) conducted a study on this cave using high-resolution continuous $\mathrm{CO}_{2}$ and internal and external temperature data. Low concentrations of $\mathrm{CO}_{2}$ were seen in periods of denser external air ventilating the cavity, while high concentrations were seen in periods of low ventilation. These patterns were seen on an annual and diurnal scale (Milanolo and Gabrosvek, 2009). Similar airflow control of $\mathrm{CO}_{2}$ has been shown in studies across Europe (Spötl et al., 2005; Baldini et al., 2006b; Pla et al., 2016) and in Florida (Gulley et al. 2014).

Previous work has been done on Blowing Springs Cave using stable carbon isotopes to characterize carbon cycling (Knierim, 2015). They concluded that cave air $\mathrm{CO}_{2}$ and cave water DIC showed carbon isotopic disequilibrium. Gaseous $\mathrm{CO}_{2}$ in the cave air was transported from 
the cave atmosphere ventilation system and from the soil zone. Aqueous DIC in the cave was sourced from soil $\mathrm{CO}_{2}$ and carbonate-bedrock dissolution. (Knierim, 2015).

\section{Objective}

The goals of this study were to: 1) examine the interactions among cave ventilation processes, $\mathrm{CO}_{2}$ gas within a cave atmosphere, and dissolved $\mathrm{CO}_{2}$ within a cave stream, and 2) to quantify the $\mathrm{CO}_{2}$ budget for a cave system, accounting for both dissolved and gaseous components. To accomplish these goals, time series measurements of the $\mathrm{CO}_{2}$ concentrations in air and water were collected in Blowing Springs Cave. Ultimately, the observations were used to examine the diurnal and seasonal changes in gaseous and dissolved $\mathrm{CO}_{2}$ and explore the extent to which to the air and water systems interact.

Blowing Springs was chosen as our study site location because: 1) Blowing Springs Cave allows access to an extended flow path ( 1000 m long) where $\mathrm{CO}_{2}$ is exchanging between the air and water along a cave stream, 2) Blowing Springs is known to have strong seasonal ventilation patterns (Knierim et al. 2017), and 3) proximity to the University of Arkansas enables frequent visits to collect data. 


\section{METHODS}

\section{Time Series Data}

Blowing Springs Cave is equipped with various sensors recording data continuously, to examine the seasonal and diurnal patterns the cave exhibits. The main data logging station is located 120 meters inside the cave along the cave stream passage. $\mathrm{CO}_{2}$ time series data were recorded at 1-hour intervals in the air and water to assess patterns and exchange of gaseous and dissolved $\mathrm{CO}_{2}$. Wind velocity and direction, barometric pressure, and external and internal air temperature were continuously recorded at 1-hour intervals, to examine mechanisms driving airflow. The primary data logging station in the cave is equipped with a Campbell Scientific CR800 data logger. The station is powered by two 12-volt $20 \mathrm{~A}-\mathrm{h} \mathrm{Li}$-ion batteries, that require replacement once a month. The Campbell's WindSonic two-dimensional sonic anemometer measures wind velocity and direction. It is bolted to the cave passage roof in the center of the cave channel to produce the best measurement possible. To measure temperature and relative humidity the Campbell's HC2S3 probe was used. Barometric pressure was measured using Campbell's CS106 sensor. In addition to the Campbell data logger, the external air temperature was measured using a HOBO U20L-04 Water Level, barometric pressure, temperature logger mounted onto a tree trunk within a PVC tube across the gravel parking lot opposite the cave entrance.

Recent technological advances have enabled high resolution time series measurements of dissolved $\mathrm{CO}_{2}$ using a $\mathrm{CO}_{2}$ gas sensor coated in a waterproof breathable membrane (Johnson et al., 2010). $\mathrm{CO}_{2}$ concentrations in the air and water were measured using two Vaisala GMM220 infrared gas $\mathrm{CO}_{2}$ sensors protected with a water-proof breathable membrane. One sensor was 
placed in the stream and one in the air. Time series data were taken from spring of 2014 to spring of 2017.

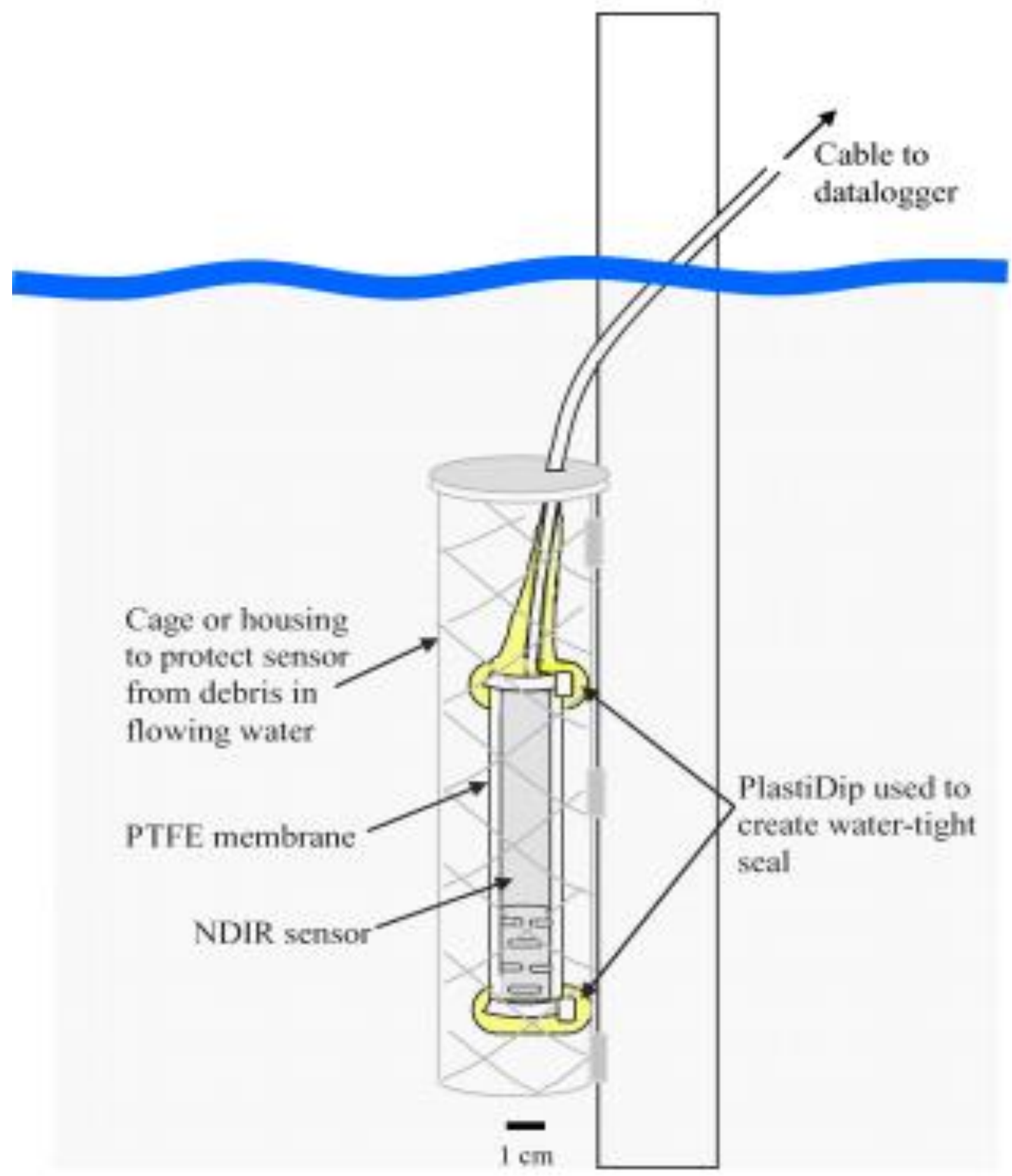

Figure 2: Diagram of the Vaisala GMT220 $\mathrm{CO}_{2}$ sensor deployed in situ. (Johnson et al. 2010) 


\section{Quality Control}

To maintain integrity of the time-series, spot measurements of $\mathrm{CO}_{2}$ in the air and water, air temperature, and cave airflow velocity were taken during monthly field visits to the site. Spot measurements were compared to the time-series data to check accuracy.

Spot measurements of $\mathrm{CO}_{2}$ in the air and water were measured using a Vaisala infrared gas $\mathrm{CO}_{2}$ sensors with a water-proof breathable membrane. The cross-sectional wind velocity spot measurements were measured to check the accuracy of the time series wind velocity data and the difference of velocity throughout the width of the passage.

\section{$\mathrm{CO}_{2}$ Longitudinal Profiles}

In addition to the time series data, spot measurements were taken of $\mathrm{CO}_{2}$ in the air and water along the length of the cave stream. Conductivity and temperature were measured at the same sites using a handheld meter. The spot measurements were taken at the entrance (BS01), the logger station (BS02), the first infeeder (BS03), the dome (BS05) and the sump (BS07) to quantify $\mathrm{CO}_{2}$ variation longitudinally along the cave stream (Figure 3). At each location the sensor was placed in the water for $30 \mathrm{~min}$ for the sensor to equilibrate, then placed in the sensor in the air for only a minute or two (equilibration occurred must faster in the air than in water due to the higher diffusivity of $\mathrm{CO}_{2}$ in air). The spot measurements were taken once during the winter, fall and summer. 


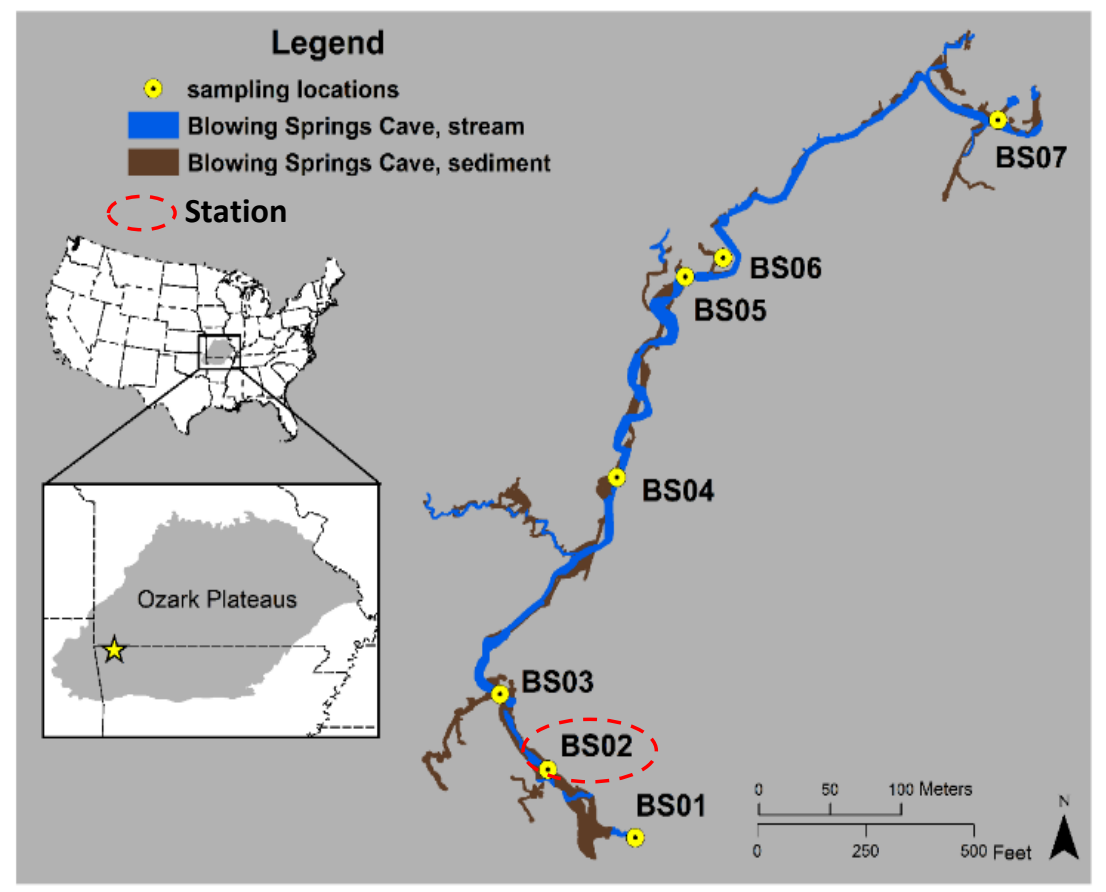

Figure 3: Blowing Springs Cave is located on the Springfield Plateau of the Ozarks (Shown with star on inset). A gaining sump near BSO7, infeeders along the cave passage, and drip water (BSO6) contribute to the flow to the cave stream, flowing from BSO7 to the entrance BS01. BSO2 is where the station is located. (Knierim, 2015)

Wind Velocity Cross Section

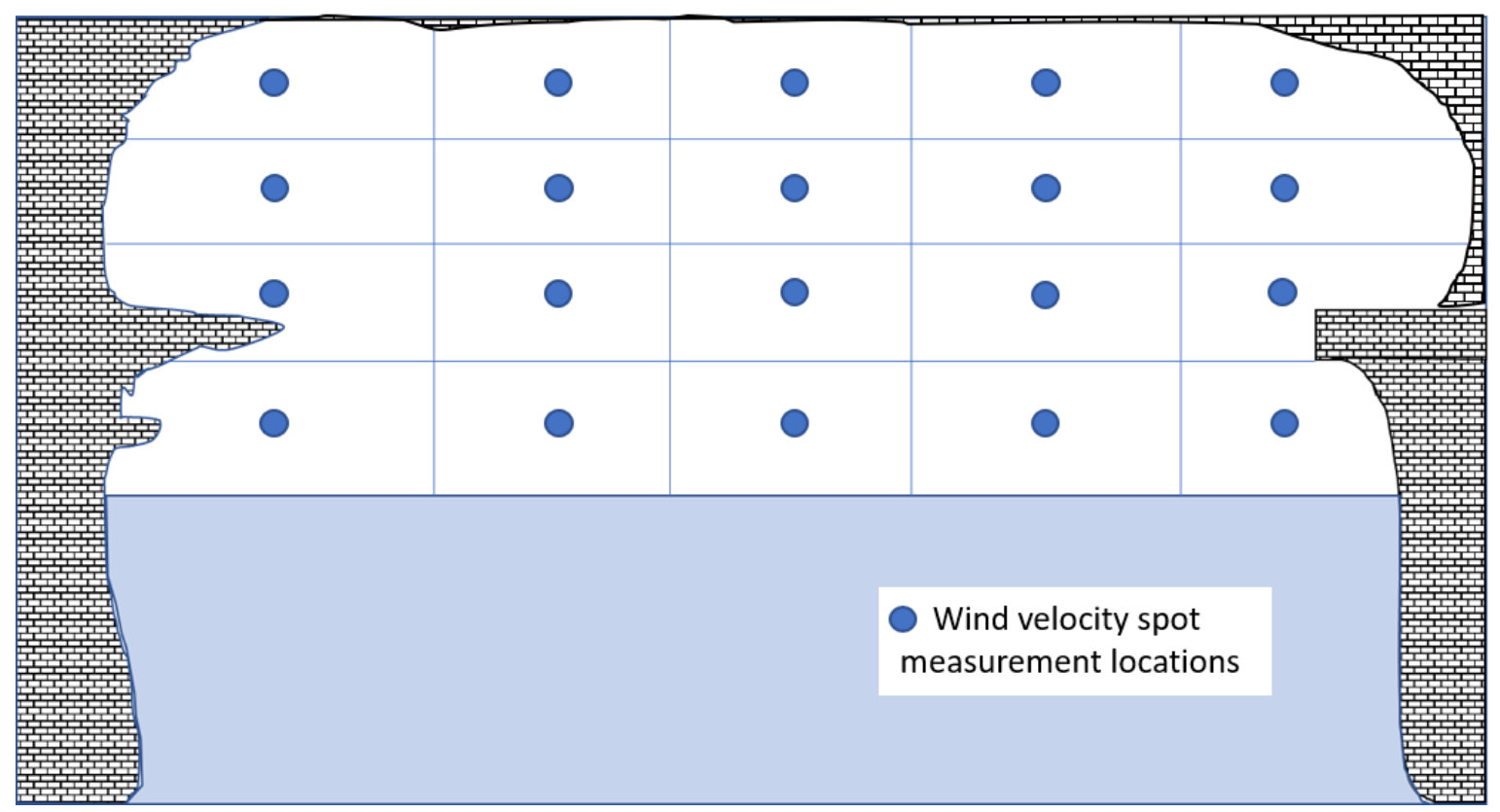

Figure 4: Diagram of the cross section of the cave where measurements of wind velocity were taken. Wind velocity measurements were taken in the center of each square in the grid. 


\section{$\mathrm{CO}_{2}$ Volume Flux in Air}

To calculate the total budget of carbon dioxide fluxes in the air of the cave, air discharge at the $\mathrm{CO}_{2}$ station was calculated using the Campbell WindSonic sensor and the spot measurements of wind velocity throughout the cross section. A 4x5 cross sectional grid sectioned the passage into 20 boxes shown in Figure 4. Spot wind velocity measurements were taken in the center of each section of the grid, using a wind velocity sensor and a tripod, to calculate an accurate wind velocity across the stream. At each wind velocity measurement point we would average wind velocity over one minute. The area of each section within the $4 \times 5$ grid was then measured by taking the distance from each spot measurement location from each adjacent location or cave wall. Using the individual wind velocity spot measurements and areas, an airflow discharge was calculated in each section. A total air discharge was then calculated for the entire cross section by summing the individual contributions. Wind velocity spot measurements were taken once in the winter, fall and summer, and twice in the spring.

These 5 air discharge measurements were plotted against the Campbell wind velocity data measured at the date and time the spot measurements were taken. Cave air discharge was then estimated from a linear regression model between the wind velocity cross section measurements and the station wind velocity measurements.

The net mass flux of $\mathrm{CO}_{2}$ in the air was then calculated using a modified version of the ideal gas law (Eq. 3) and a flux calculation (Eq. 4) to create equation _. First, the ideal gas law:

$$
P V=n R T
$$


where $\mathrm{P}$ is pressure, $\mathrm{V}$ is velocity, $\mathrm{n}$ is the number of moles of gas, $\mathrm{R}$ is the gas constant .08206 $\mathrm{L}$ atm, and $\mathrm{T}$ is temperature in kelvin. To manipulate this equation to find mass net flux, $\mathrm{n}$ is changed to $\mathrm{m}$ (mass in grams)/ M (molar mass) to get:

$$
P V=\frac{m}{M} R T
$$

The modified ideal gas law is then rearranged to find $\mathrm{m}$, mass in grams:

$$
m=\frac{P V M}{R T}
$$

This modified gas law is combined with a flux calculation substituting discharge as velocity and $\mathrm{PCO}_{2}$ as pressure to create the final mass net flux equation:

$$
F_{\mathrm{CO}_{2} \text { air }}=\frac{Q_{\text {air }}\left(P_{\mathrm{CO}_{2 a}}-P_{\mathrm{CO}_{2} a t \mathrm{tm}}\right) M_{\mathrm{CO} 2}}{R T},
$$

where $F_{\mathrm{CO}_{2} \text { air }}$ is the mass net flux of $\mathrm{CO}_{2}$ in the air $(\mathrm{g} / \mathrm{sec}), Q_{\text {air }}$ is the air discharge $(\mathrm{L} / \mathrm{sec})$,

$P_{\mathrm{CO}_{2} a}$ is the partial pressure of $\mathrm{CO}_{2}$ in the air in atm measured from the Campbell Station,

$P_{C_{2}{ }_{2} \text { atm }}$ is the atmospheric concentration of $\mathrm{CO}_{2}(0.0041 \mathrm{~atm}), M_{\mathrm{CO} 2}$ is the molar mass of $\mathrm{CO}_{2}$ in $\mathrm{g} / \mathrm{mol}(44.01 \mathrm{~g} / \mathrm{mol}), R$ is the gas constant $(.08206 \mathrm{~L} * \mathrm{~atm} / \mathrm{mol} * \mathrm{~K})$ and $\mathrm{T}$ is temperature $(288.15$ K).

\section{Calculating Stream Discharge}

To estimate stream discharge at Blowing Springs, a regression to the Little Sugar Creek USGS station 07188838 was applied. Little Sugar Creek is approximately $20 \mathrm{~km}$ northwest of our site but has been previously shown to have a strong correlation with the Blowing Springs discharge (Kneirim et al. 2015). 


\section{Mass Flux of Dissolved $\mathrm{CO}_{2}$}

The flux of $\mathrm{CO}_{2}$ within the water column was estimated using Henry's Law to calculate dissolved $\mathrm{CO}_{2}$ from the Campbell $\mathrm{CO}_{2}$ concentrations using the equation:

$$
\left[\mathrm{CO}_{2}\right]_{w}=\mathrm{P}_{\mathrm{CO}_{2}} / K_{\mathrm{H}}
$$

where $\left[\mathrm{CO}_{2}\right]_{w}$ is the concentration of dissolved $\mathrm{CO}_{2}$ in mol/L, $P_{\mathrm{CO}_{2}}$ is the measured $\mathrm{CO}_{2}$ partial pressure in atm, and $\mathrm{K}_{\mathrm{H}}$ is Henry's Law constant for $\mathrm{CO}_{2}$ at $288.15 \mathrm{~K}(21.92 \mathrm{~atm} / \mathrm{M})$.

Using the estimated stream discharge from the Little Sugar Creek USGS discharge data and the measured $\mathrm{CO}_{2}$ time series, the net mass flux of $\mathrm{CO}_{2}$ in the water was calculated using

$$
Q_{\mathrm{CO} 2}=Q_{\text {Stream }}\left(\left[\mathrm{CO}_{2}\right]_{w}-\left[\mathrm{CO}_{2}\right]_{a t m}\right) M_{\mathrm{CO} 2}
$$

where $Q_{\mathrm{CO} 2}$ is mass net flux of $\mathrm{CO}_{2}$ in the water $(\mathrm{g} / \mathrm{sec}), Q_{\text {Stream }}$ is the calculated stream discharge in $\mathrm{L} / \mathrm{sec},\left[\mathrm{CO}_{2}\right]_{w}$ is the concentration of $\mathrm{CO}_{2}$ in $\mathrm{mol} / \mathrm{L},\left[\mathrm{CO}_{2}\right]_{\text {atm }}$ is the atmospheric concentration of $\mathrm{CO}_{2}(0.000018 \mathrm{~mol} / \mathrm{L})$ and $M_{C O 2}$ is the molar mass of $\mathrm{CO}_{2}$ in $\mathrm{g} / \mathrm{mol}(44.01$ $\mathrm{g} / \mathrm{mol}$ ). 


\section{STUDY SITE DESCRIPTION}

Northwest Arkansas is located within the Ozark Plateaus Province (OPP). The OPP is separated into three distinct physiographic plateaus that extend into Arkansas, Oklahoma, Missouri and parts of Kansas. A structural dome underlies the OPP (Adamski et al., 1995). The OPP has undergone extensive faulting, fracturing and dissolution, which makes it one of the major karst landscapes in the US (Weary and Doctor, 2014; Hays et al., 2016).

Our study site at Blowing Springs Cave (BSC) is located within the Springfield Plateau (SP), the westernmost section of the OPP. The SP is the uppermost hydrogeologic unit of the Ozark system (Hays et al., 2016). The network of joints, fractures and faults are critically important as they provide preferential pathways, leading to dissolution processes within the carbonate rocks, widening the cavities until they were large enough to form caves (Tennyson and others, 2008; Brahana and others, 2009; Hays et al., 2016). The SP consists of gently dipping units of the Chattanooga Shale (Devonian), and Mississippian Boone. In Arkansas, the Boone Formation exclusively represents the Springfield Plateau Aquifer. Although matrix porosity and permeability in the Boone are low, dissolution along fractures is dominant. Recharge is dominated by the meteoric water flowing either diffusely or through preferential flow paths like sinkholes, fractures and losing streams (Adamski et al., 1995; Kresse et al., 2014; Knierim, 2015). The Boone Formation is a crinoidal limestone with a high chert content. Karst development is greater in the St. Joe, a relatively pure limestone, than the remainder of the Boone, because of the chert abundance in the middle Boone (Hays et al., 2016). The chert within the Boone Formation can also perch groundwater flow causing it to flow down dip until it reaches a vertical fracture or a spring (Imes and Emmett, 1994; Brahana, 1997; Knierim, 2015). 
BSC is located within the city limits of Bella Vista, in the Northwestern corner of Arkansas. Bella Vista is on the border of Arkansas and Missouri. Blowing Springs is owned and managed by the Bella Vista Property Owners Association. The cave is located inside Blowing Springs park, where it is closed off to the public with a gate. Anthropogenic $\mathrm{CO}_{2}$ sources are largely absent because of this restricted access. The entrance of the cave is approximately at an elevation of $335 \mathrm{~m}$. The cave restricted to less than $30 \mathrm{~m}$ to $45 \mathrm{~m}$ below the surface. Discharge from the spring flows to Little Sugar Creek, our discharge analog for this study (Knierim, 2015). The BSC recharge area was calculated to be between 2.9 and $6.1 \mathrm{~km}^{2}$ (Knierim et al., 2013, Knierim, 2015). BSC has $2.4 \mathrm{~km}$ of surveyed cave passages with the main passage length at approximately $800 \mathrm{~m}$ and ranging between $1 \mathrm{~m}$ to $16 \mathrm{~m}$ wide. BSC is located primarily within the St. Joe member and is formed along a combination of bedding planes and fractures, allowing vertical and horizontal movement of groundwater flow. Evidence that the Upper Boone makes up part of the cave is observed in high domes and solutionally enlarged fractures within BSC where chert layers perch groundwater flow (Knierim, 2015). BSC is a branchwork cave system with a main stream and many small infeeding streams (Figure 5). Our main logging station (BS02) is located approximately $120 \mathrm{~m}$ from the entrance (Figure 5). 


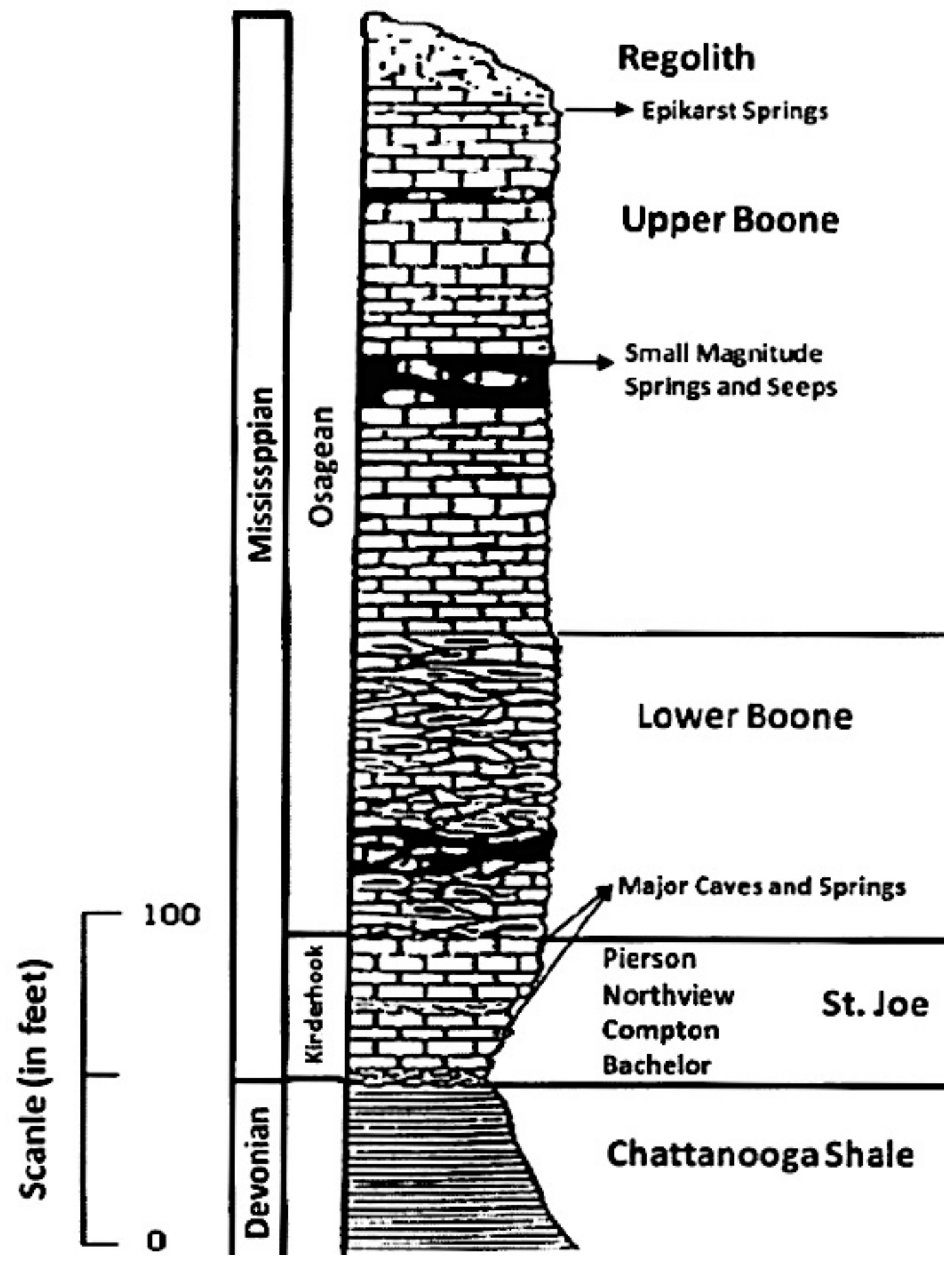

Figure 5: Hydrostratigraphic column of Northwest Arkansas (modified from AlRashidy, 1999) (Vaughn, 2015) 


\section{RESULTS}

Blowing Springs Cave shows regular shifts in airflow direction over time. In Figure 6, airflow velocity is represented over the time span of our study of $2 \frac{1 / 2}{2}$ years. In the summer months, air is primarily flowing out of the cave, and in the winter months air is primarily flowing into the cave, with minimal reversals. In the fall and spring, air transitions diurnally, blowing out during the day and blowing in at night. As these patterns repeat yearly, it is clear that seasonally controlled temperature variations drive wind velocity trends seen in Blowing Springs Cave.

Blowing Spring's seasonal airflow pattern mirrors that seen in caves where the chimney effect is prominent. As mentioned previously, the chimney effect is an airflow regime in caves with multiple entrances and is caused by temperature driven buoyancy differences between the cave and the surface air. To investigate if temperature drives the wind velocity changes in Blowing Springs, the temperature difference $\left(\mathrm{T}_{\text {ext. }}-\mathrm{T}_{\mathrm{in} .}\right)$ and wind velocity were compared over time. Figure 7, depicts the difference between internal and external air temperature over a time span of $2 \frac{1}{2}$ years. The positive values denote higher external temperature with air blowing out of the cave, while the negative values denote lower external temperatures with air blowing into the cave. Three regimes are shown in varying seasons. In winter, external air is colder and denser than the internal cave air and airflow is directed into the spring entrance. In summer, external air is lighter than the cave air, and airflow is blown out of the cave. In fall and spring, diurnal airflow reverses as temperature differences switch from positive to negative during the day and below at night.

$\mathrm{CO}_{2}$ concentrations in the air and water at Blowing Springs vary over time, both seasonally and diurnally (Figure 6). In the summer months, $\mathrm{CO}_{2}$ concentrations in the air and 


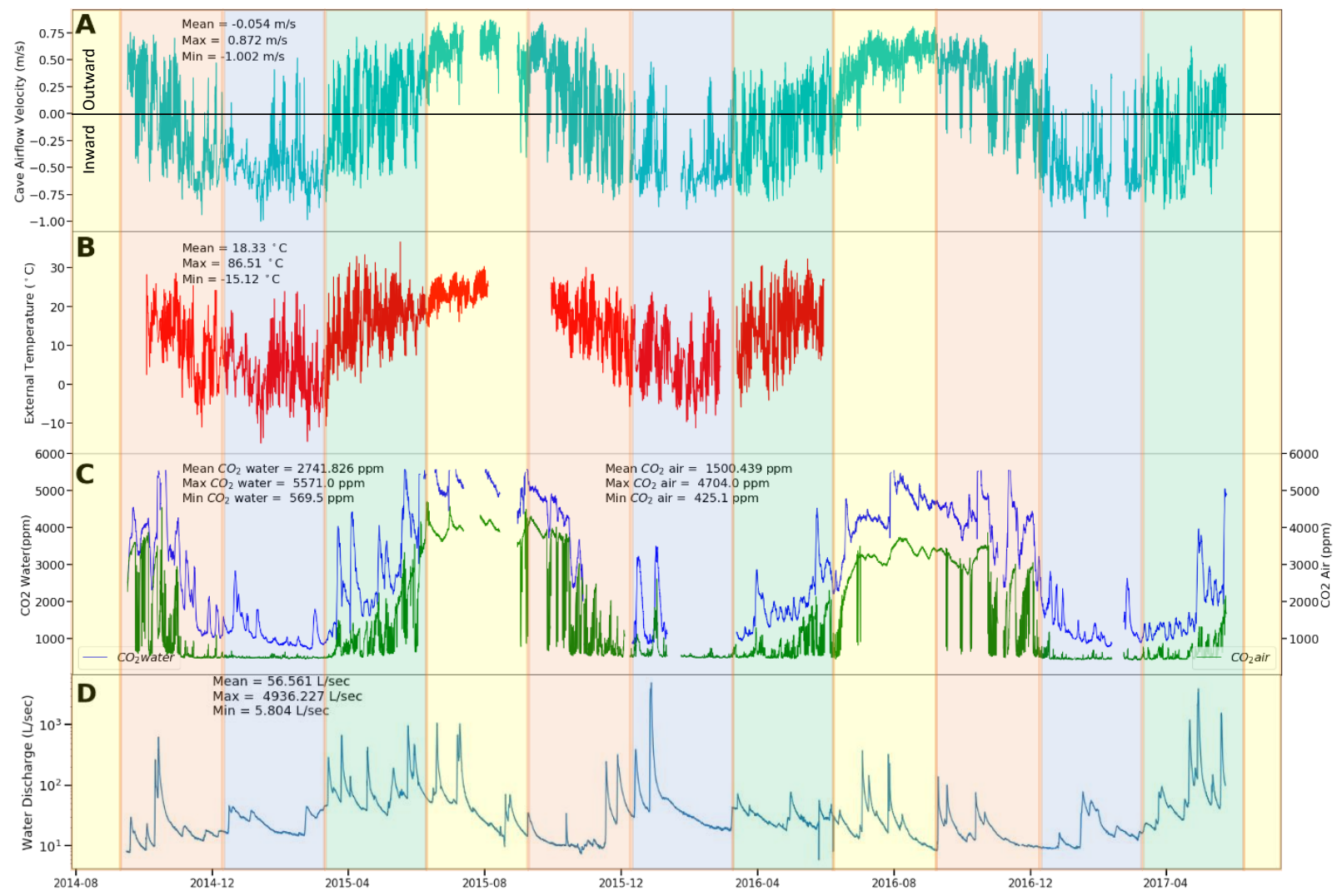

Figure 6: Time Series plots of wind velocity, external temperature, $\mathrm{CO}_{2}$ concentration in the air and water and water discharge. Mean, max and min values are given on plot. Seasons are separated with the different colors, blue is winter, green is spring, yellow is summer and orange is fall. 


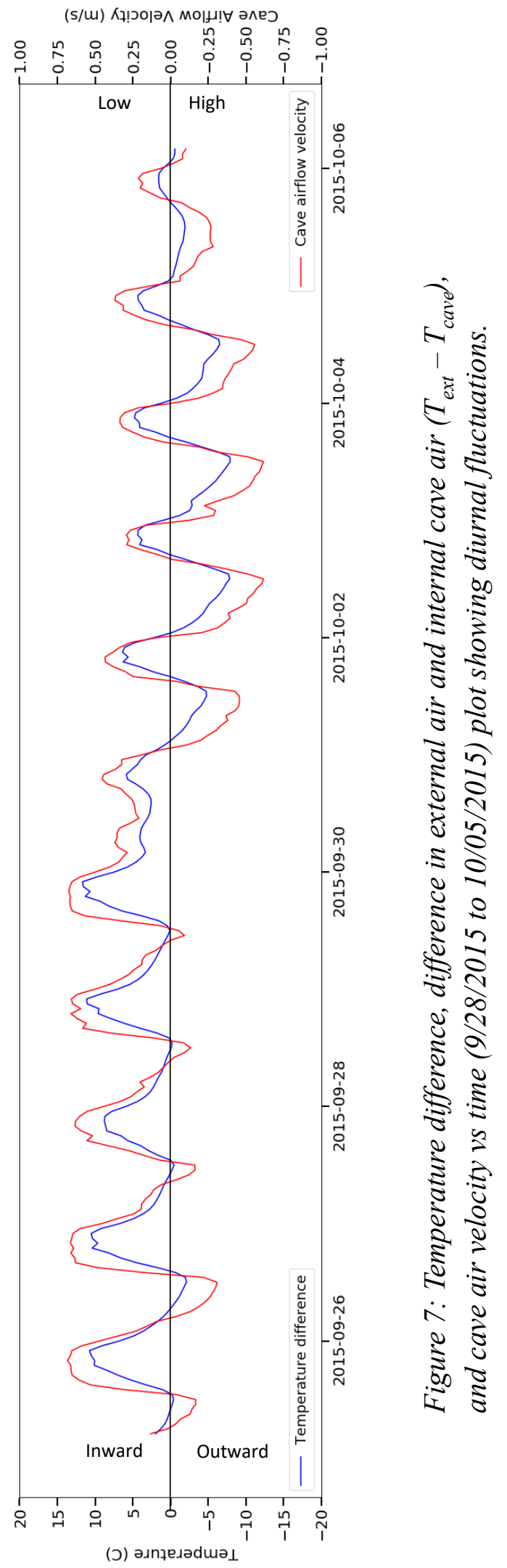


water reach their highest values. In the air, these values are $4704 \mathrm{ppm}$ and water at $5571 \mathrm{ppm}$, however the water concentration is above the maximum range of our sensor at $5000 \mathrm{ppm}$, so we do not know the actual maximum values. In the winter, $\mathrm{CO}_{2}$ concentrations reach their lowest values in the air at $425 \mathrm{ppm}$ and in the water at $569 \mathrm{ppm}$. In the transitional periods of spring and fall, noisy diurnal spikes and dips are seen. The average value for $\mathrm{CO}_{2}$ in the air is $1500.4 \mathrm{ppm}$ and in the water is $2741.8 \mathrm{ppm}$. If both time series figures of $\mathrm{CO}_{2}$ concentrations and airflow are compared, airflow and $\mathrm{CO}_{2}$ concentrations follow a similar trend with water almost always showing higher concentrations than air.

\section{Airflow Patterns}

As seen above, an airflow pattern is evident in Blowing Springs. At a smaller timescale, (Figure 7) a transitional period in a week in the fall between September $25^{\text {th }}, 2015$ and October $5^{\text {th }}, 2015$ is evident. Notice the diurnal variations, indicating spikes in airflow during the day and dips at night. These spikes and dips are due to higher external temperatures in comparison to the internal cave temperature during the day, resulting in an outward airflow, and lower external temperatures during the night, resulting in inward airflow.

A direct comparison is shown in Figure 8, plotting wind velocity against temperature difference. There is a strong relationship between the two variables. In most cases a temperature difference below zero, wind velocity is correlated to negative (blowing in) as well. When temperature difference is positive, wind velocity is positive (blowing out).

To test if temperature is the main driver of airflow patterns within Blowing Springs Cave, the barometric pressure and wind velocity were compared to see if there is any correlation 


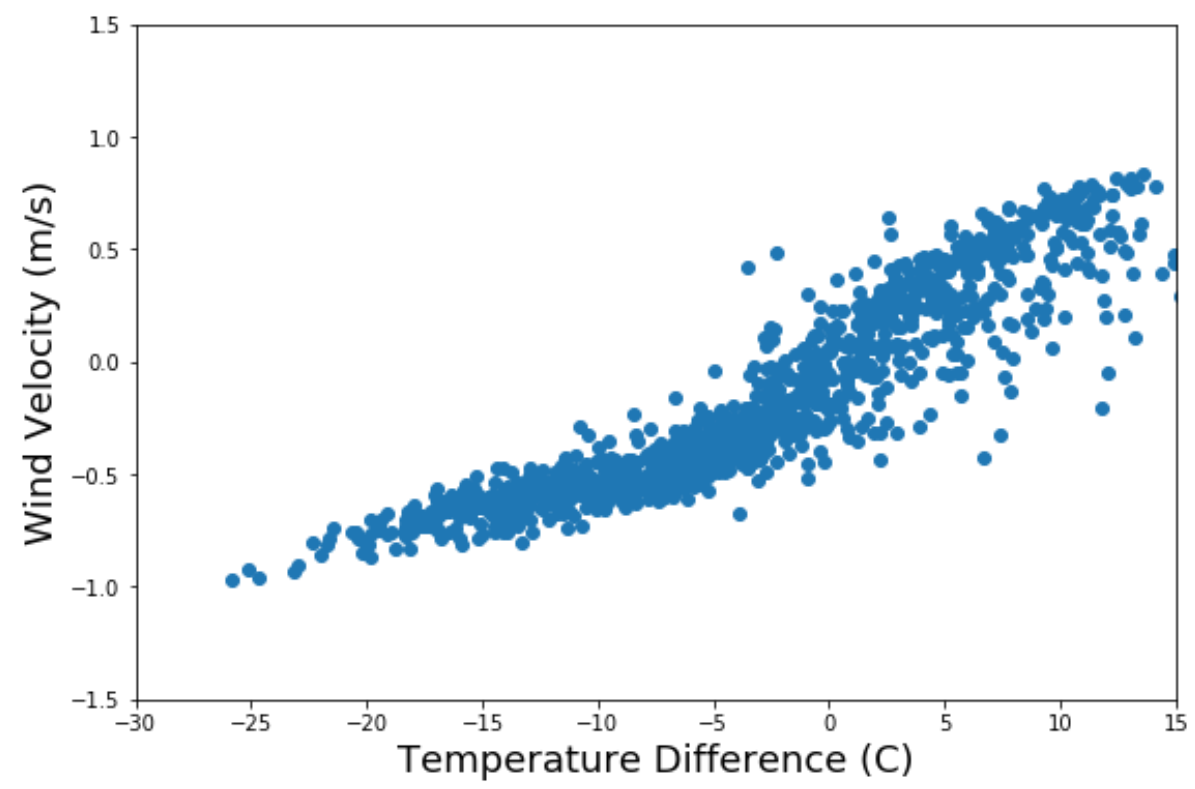

Figure 8: Wind velocity vs Temperature difference plot. Temperature difference, difference in external air and internal cave air $\left(T_{\text {ext }}-T_{\text {cave }}\right)$.

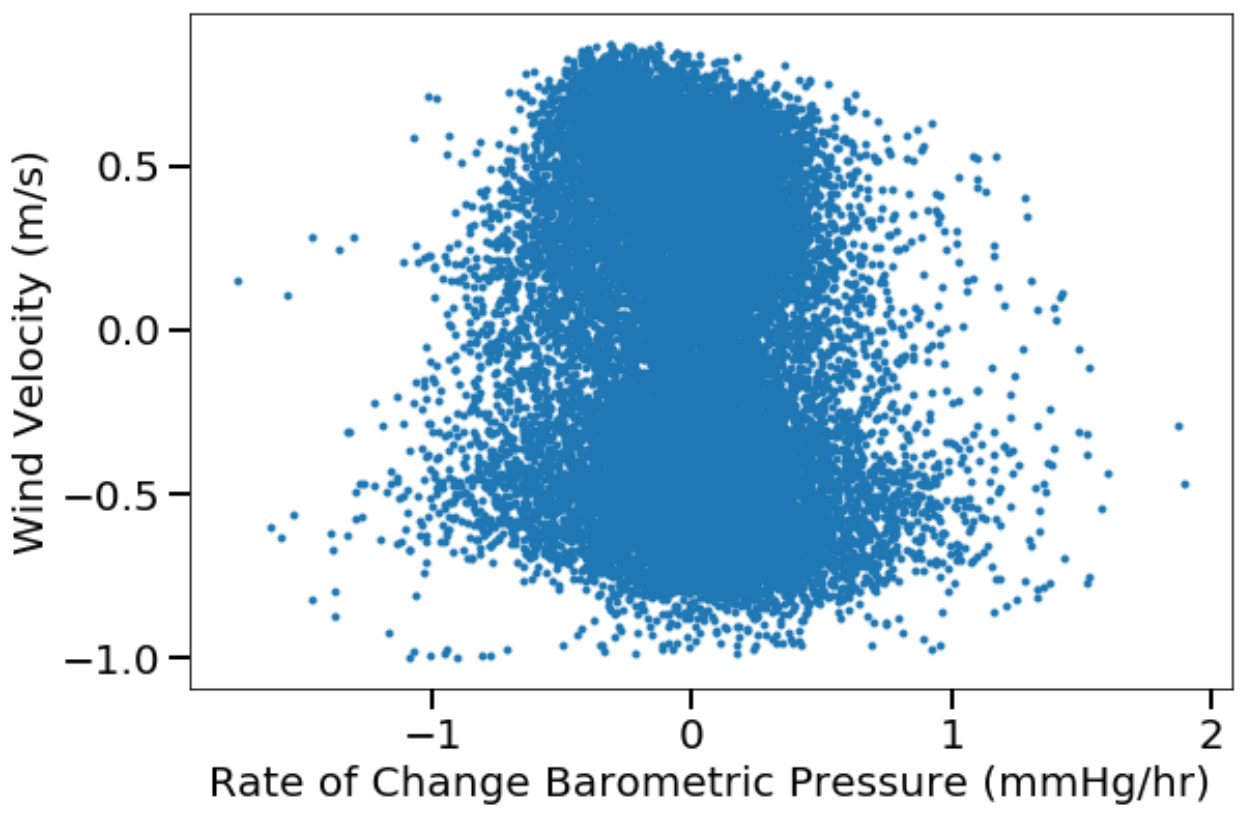

Figure 9: Rate of Change of Barometric Pressure vs wind velocity plot. Rate of change of BP was found by taking the derivative of $B P$. 
(Figure 9). Figure 9 represents the comparison between a derivative of barometric pressure, found by taking the derivative of the barometric pressure values using a SavitzkyGolay filter, and wind velocity. Taking the derivative of barometric pressure is necessary because the change in the barometric pressure is what is relevant to determine if pressure drives airflow and not just the values. The two variables do not show any type of correlation, showing an unsorted scatter plot.

\section{$\mathrm{CO}_{2}$ Analysis}

To examine the $\mathrm{CO}_{2}$ concentration patterns at a smaller time scale, a comprehensive plot of $\mathrm{CO}_{2}$ concentrations in the air and water and wind velocity was created to examine their direct relationship with each other (Figure 10) during the same week in the fall. Diurnal variations of $\mathrm{CO}_{2}$ are evident with the spikes and troughs like those of airflow. High concentrations are seen during daytime hours, low concentrations are seen during the night. The timing of the airflow reversals aligns with changes in air $\mathrm{CO}_{2}$.

In Figure 10, almost directly after an airflow reversal, seen in the wind velocity peaks and troughs, the air $\mathrm{CO}_{2}$ concentration immediately responds, spiking or dipping corresponding to the wind velocity. The $\mathrm{CO}_{2}$ concentrations in water respond to these reversals, following the same general trend, but slightly delayed. It appears the water response is delayed as it takes time to equilibrate to the concentration changes in the air.

\section{Lag}

To measure the time scale of $\mathrm{CO}_{2}$ gas transfer between the air and the stream, the cross correlation between the two time series were calculated. Cross correlation measures the similarity of two time series as a function of the displacement (time lag) between the two. Points 


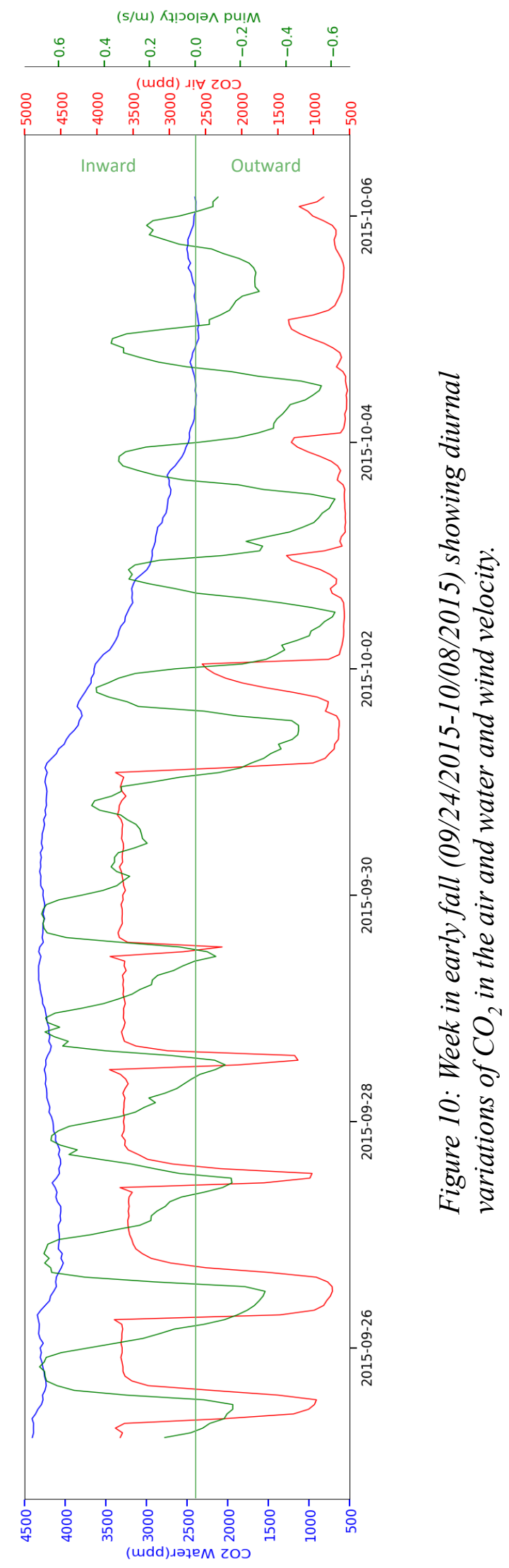


of similarity are depicted by the peaks in the cross correlation. To examine the lag time associated with gas exchange under a variety of conditions, cross correlations for different seasons and time frames were plotted.

To examine the lag time during the visible diurnal patterns in a week time frame, two separate cross correlations where taken during a week in late September early October (Figure 11 \& 12). The first cross correlation was produced at $9 / 24 / 2015$ to $10 / 01 / 2015$ where $\mathrm{CO}_{2}$ concentrations were consistently high but show dips in the concentrations at night (Figure 11). Similarities were seen daily with large peaks at $1 / 2$ a day and between 5 and 6 days. The time series shows a slight response immediately and then the response slows, taking roughly a day to 5 days to respond. The second cross correlation in Figure 12 was produced during 10/01/2015 to 10/08/2015 where $\mathrm{CO}_{2}$ concentrations were constantly low with spikes during the day. Similarities were seen daily with large peaks at 1,2 and 7 days. The water concentration variations are so slight within the time series plot making it is difficult to interpret, which small peak correlates with the air peaks.

Figure 13 shows the time series in the winter of 2014/2015 from 11/1/2014 to 3/1/2015. The entire winter of 2014/2015 the air concentrations remained very low with small spikes, only once reaching slightly above $1000 \mathrm{ppm}$. The water concentrations reached considerably low values and varied within a larger range than the air concentrations did. The spikes in the water mirror rain events seen in the water discharge rather than the small spikes in the air.

During the summer, concentrations stay relatively high. Figure 14, shows a time series plot during 6/01/2016 to 9/01/2016 where the concentrations in the water and air stay relatively high with little noise. Interestingly, the water experiences a few steep spikes not mirrored in the air. 

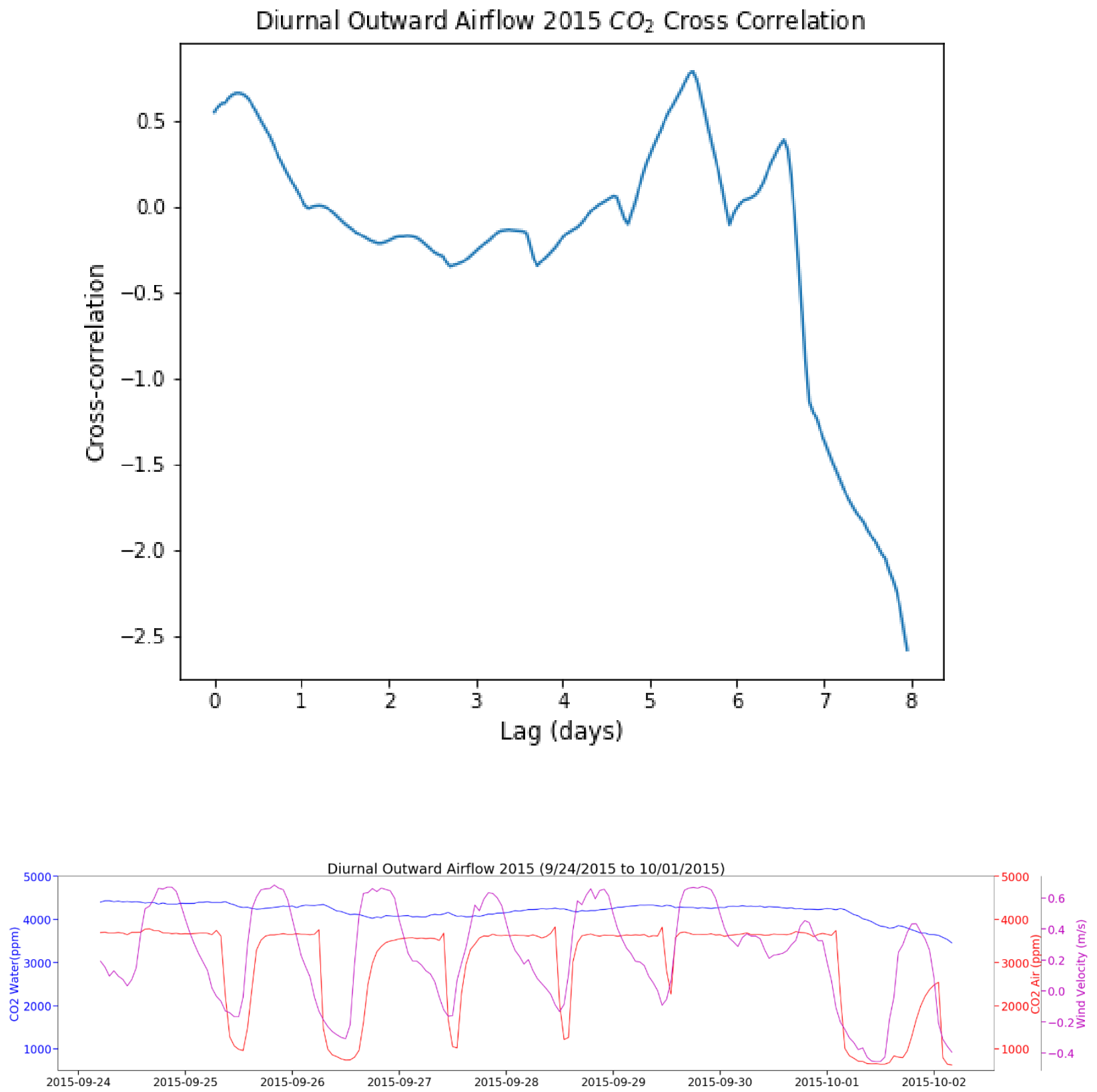

Figure 11: Cross Correlation and time series of CO2 in the air and water from 09/24/2015 to 10/01/2015. Airflow is outward. 

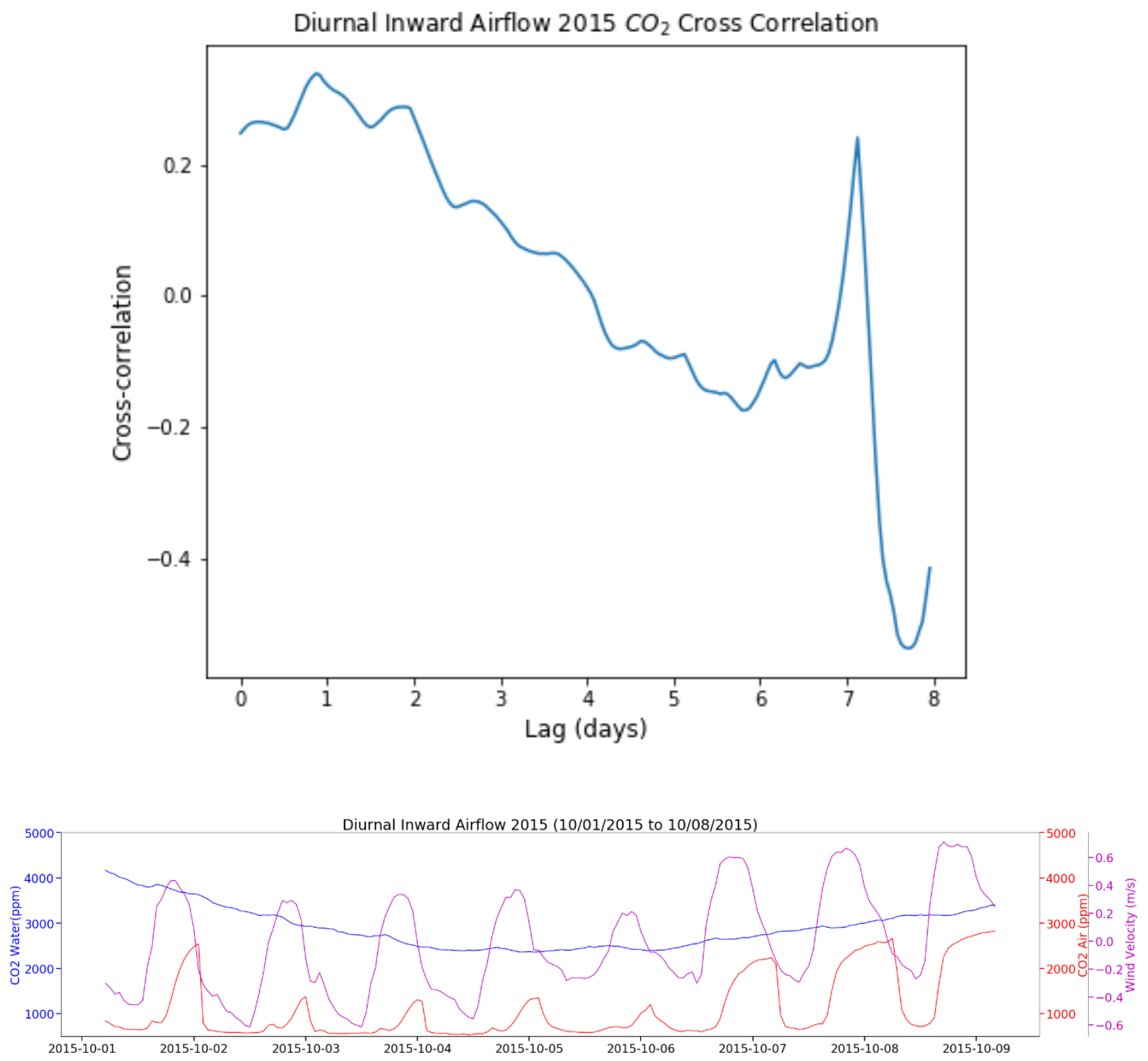

Figure 12: Cross correlation and time series of $\mathrm{CO} 2$ in the air and water from 10/01/2015 to 10/09/2015. Airflow is inward. 

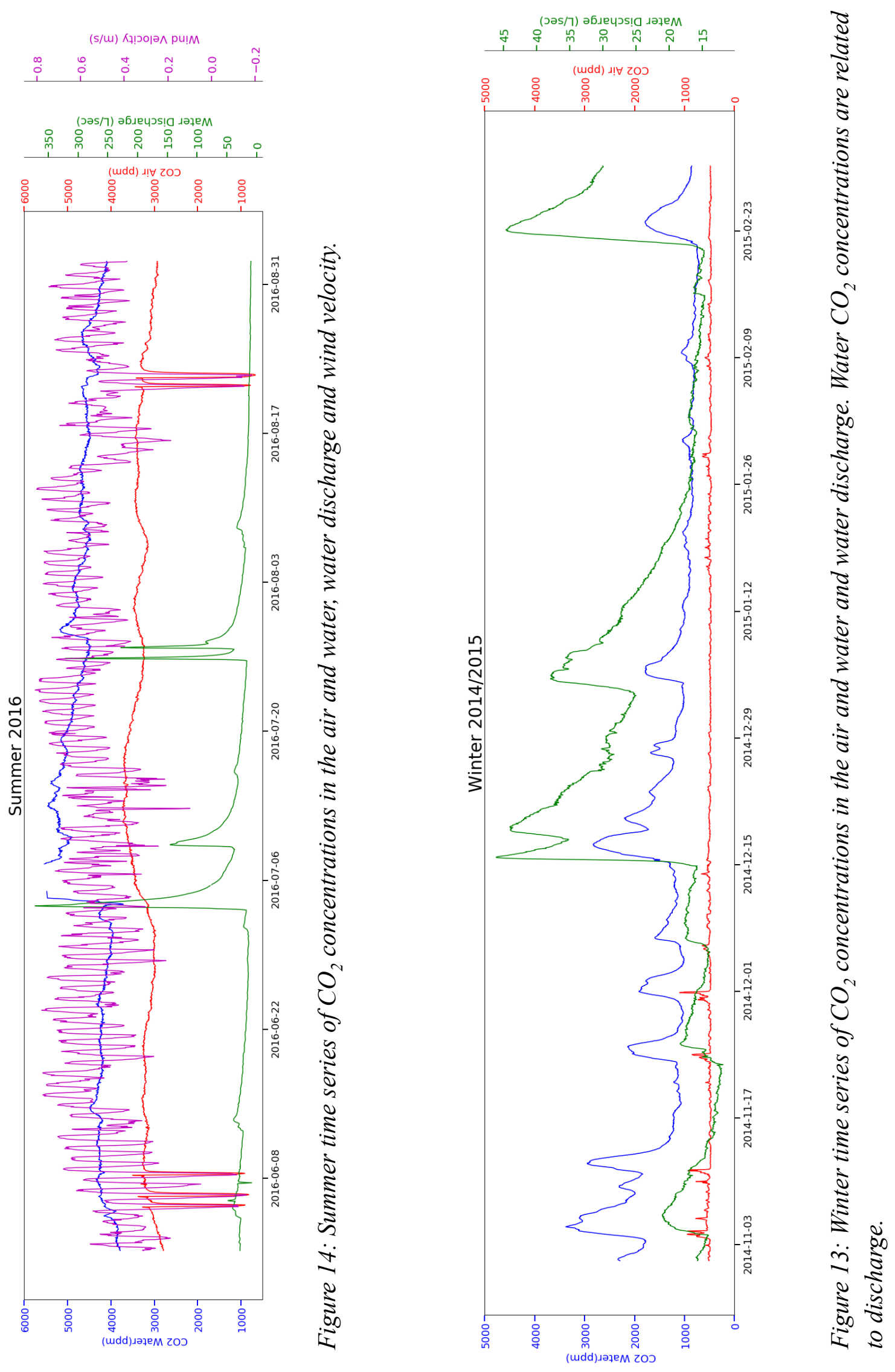


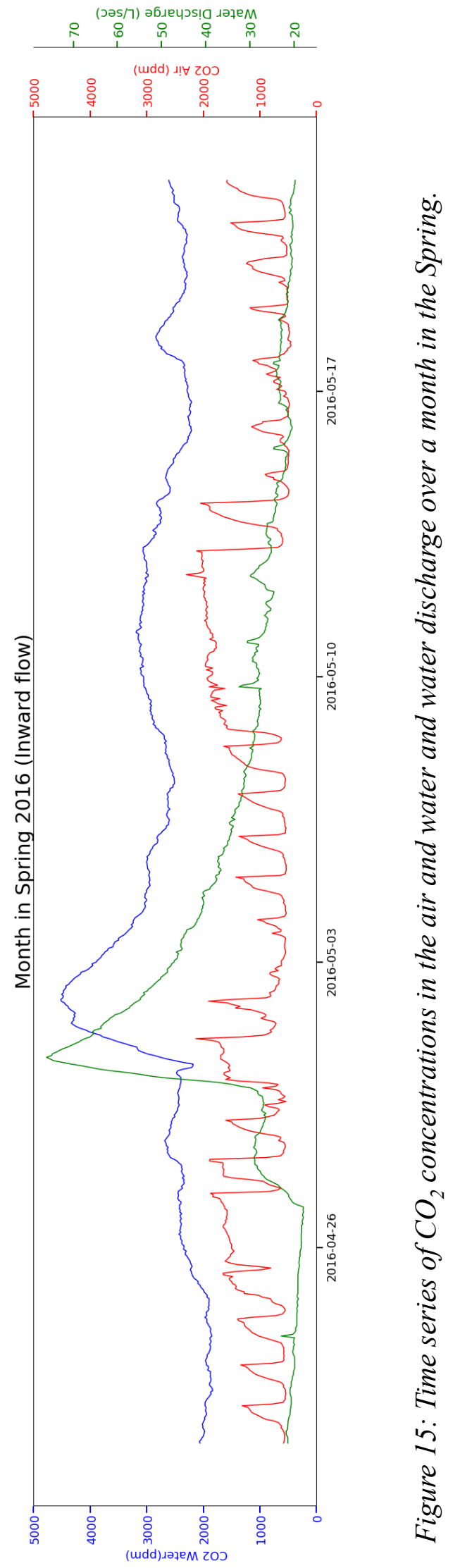


Transition seasons in the fall and spring show visible diurnal patterns in wind velocity and $\mathrm{CO}_{2}$ concentrations. To examine the lag time during these diurnal transitions, a month time span during the spring of 2016 was observed (Figures 15), with generally high concentrations during the day with dips during the night. The first timeseries is a month in the spring of 2016, where the concentrations remain relatively low with spikes during the day. Concentrations in the air, spiking during the day, with water concentrations showing a very smooth trend slightly following the general air trend, (Figure 15). At around day 10 there is a large spike in the water discharge that is not seen in the air $\mathrm{CO}_{2}$ concentrations but is seen in water $\mathrm{CO}_{2}$ concentrations.

\section{Longitudinal $\mathrm{CO}_{2}$ Profiles}

Since our high-resolution time series $\mathrm{CO}_{2}$ data are limited to only one location in the cave, $\mathrm{CO}_{2}$ longitudinal profiles in the air and water were taken on 5/12/2016, 10/9/2016, $1 / 28 / 2017$, dates spanning a variety of seasonal conditions to examine exchange of $\mathrm{CO}_{2}$ along the entire accessible flow path. Spot measurements of $\mathrm{CO}_{2}$ concentrations were taken in the air and water along the cave stream at 5 locations, shown on the map in Figure 16, once in the fall, winter and summer. These locations were labeled as BSO1, BSO2, BSO3, BSO5, and BSO7, with BSO1 being located at the entrance, and the other stations being located approximately $120 \mathrm{~m}, 200 \mathrm{~m}, 450 \mathrm{~m}$, and $800 \mathrm{~m}$ upstream of the entrance, respectively. BSO2 is the same location as the $\mathrm{CO}_{2}$ station, and the furthest upstream station, $\mathrm{BSO}$, was located at the upstream sump. For all seasons the $\mathrm{CO}_{2}$ concentrations in both air and water trended from lower concentrations at the entrance to higher concentrations at the sump. There are several exceptions to this trend, with spikes in $\mathrm{CO}_{2}$ concentrations in the air and water seen at the $\mathrm{CO}_{2}$ station (BSO2) during the winter and summer surveys. These anomalously high readings may result 
from a longer presence of the team at this site, during which time we were producing $\mathrm{CO}_{2}$ from our own respiration, but this may only explain the air concentrations and not the water.

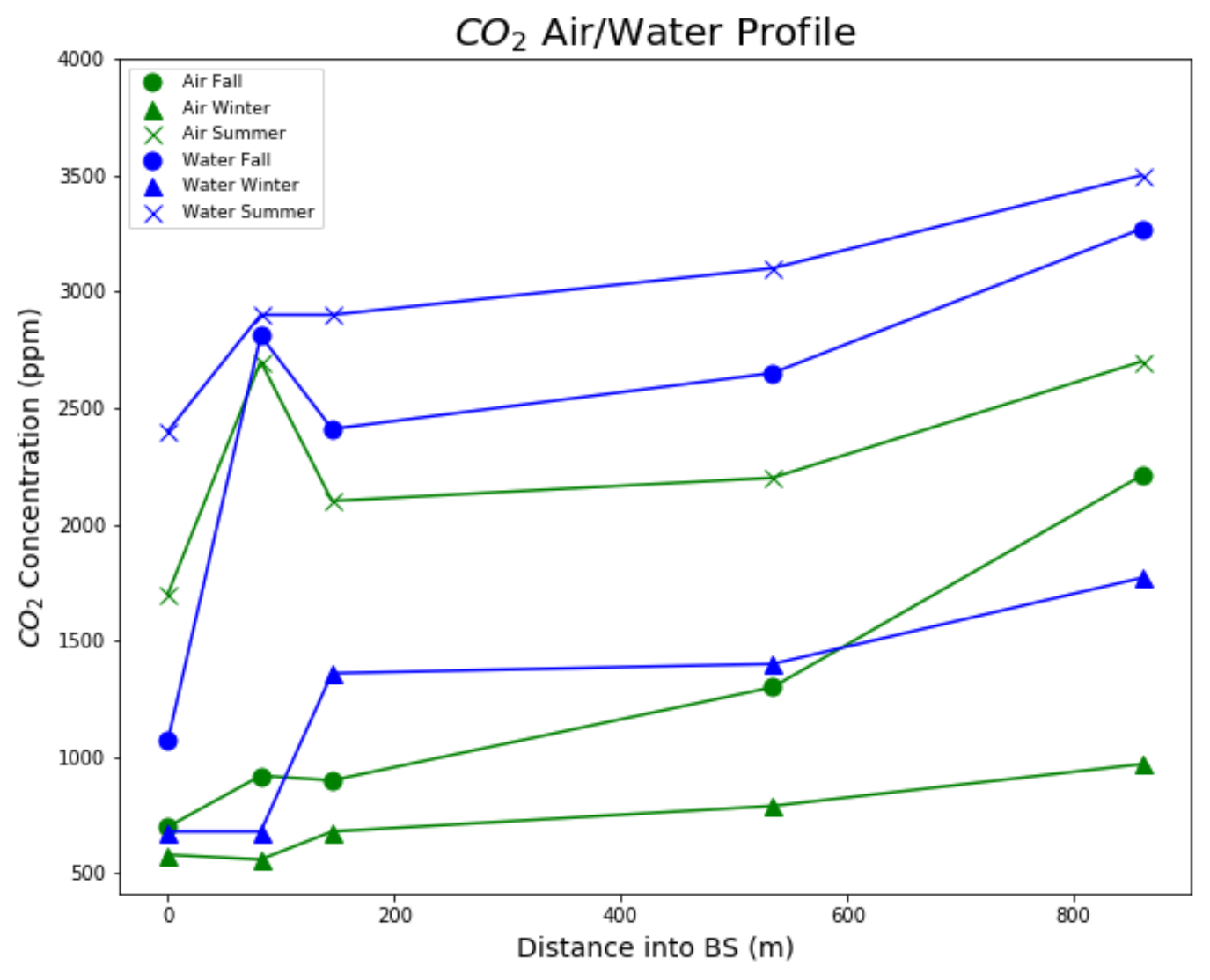

Figure 16: Spot $\mathrm{CO}_{2}$ Profile. $\mathrm{CO}_{2}$ measurements were taken once during the Fall, Winter and Summer in the air and water at 5 stations throughout the cave. 
$\mathrm{CO}_{2}$ exchange rates are roughly proportional to the differences in $\mathrm{CO}_{2}$ in the air and water. When $\mathrm{CO}_{2}$ differences in the air and water are high, exchange rates are high because there is a greater need to equilibrate. To examine exchange rates we plotted the $\mathrm{CO}_{2}$ differences in the air and water during each season at every station was plotted (Figure 17). The difference or exchange of $\mathrm{CO}_{2}$ appears to be higher in the fall than the winter and summer. In the summer, the station with the highest exchange is at BS05 with the lowest at the entrance. In the winter, BS07 has the highest exchange and both the entrance and the station have the lowest exchange.

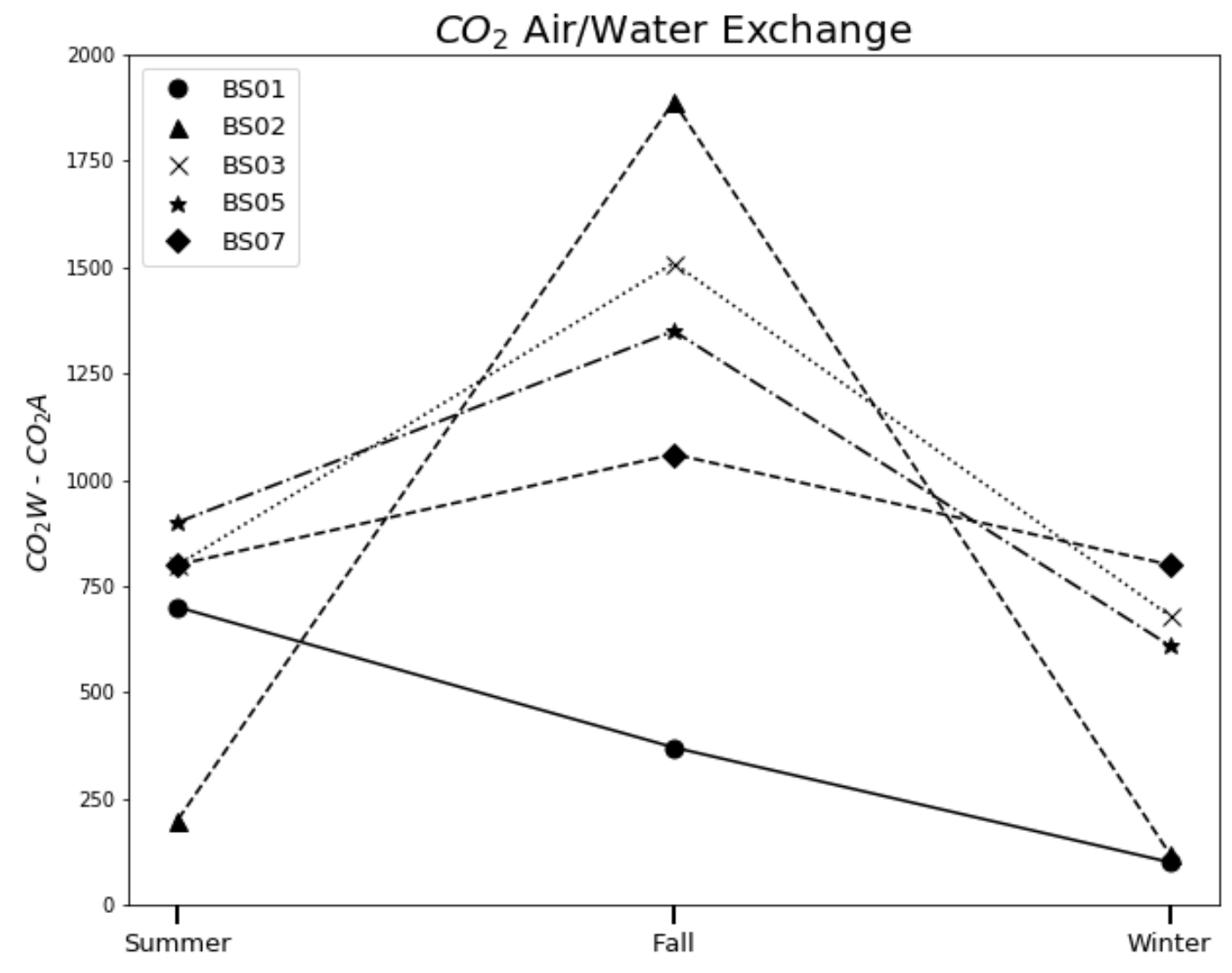

Figure 17: $\mathrm{CO}_{2}$ air water exchange representation using the spot measurements in Figure 15. Exchange is proportional to the difference between $\mathrm{CO}_{2}$ in the air and water at each station. 


\section{$\mathrm{CO}_{2}$ Budget}

A primary goal of this study was to quantify the $\mathrm{CO}_{2}$ flux through the cave system. The two main pathways for the transport of $\mathrm{CO}_{2}$ gas are in the air and the stream, and therefore $\mathrm{CO}_{2}$ fluxes in the air and water were quantified and compared.

Figure 18 depicts the continuous air $\mathrm{CO}_{2}$ flux time series over a $2 \frac{1}{2} 2$ year timespan. The mean, max and min values of air $\mathrm{CO}_{2}$ flux in $\mathrm{g} / \mathrm{s}$ was also calculated at 1.738, 12.994 and -2.656. The yearly outward $\mathrm{CO}_{2}$ flux was calculated by taking the sum of air $\mathrm{CO}_{2}$ flux over an entire year. The outward $\mathrm{CO}_{2}$ flux in 2015 in the air is $153,843,477.1 \mathrm{~g} / \mathrm{yr}$ and in 2016 it is 124,704,729.2 g/yr. Inward airflow $\mathrm{CO}_{2}$ flux in 2016 was 4,997.53 g/yr. The inward flow regime flux was roughly calculated using Eq. 5, with the air spot measurement at BS07 in the winter in place for $P_{\mathrm{CO}_{2}}$ and the mean discharge on the date of the sample in place of $Q_{a i r}$, then multiplied by the number of negative values of airflow in 2016. Total $\mathrm{CO}_{2}$ flux in the air in 2016 was $124,709,726.73 \mathrm{~g} / \mathrm{yr}$. Figure 18 shows the air discharge during the study period of $21 \frac{1}{2}$ years. Air discharge, which was calculated from a linear regression model between the wind velocity cross section measurements and the station wind velocity measurements, appear to be closely related to the $\mathrm{CO}_{2}$ air flux as they follow the same trend.

Figure 18 shows the water $\mathrm{CO}_{2}$ flux over a time span of $2 \frac{1}{2}$ years, which reflects a hydrograph. The mean, max and min values of water $\mathrm{CO}_{2}$ flux in $\mathrm{g} / \mathrm{sec}$ were observed at 110.481, 5652.674 and 5.339. The yearly water $\mathrm{CO}_{2}$ flux was calculated by taking the sum of water $\mathrm{CO}_{2}$ flux over an entire year. The mass water $\mathrm{CO}_{2}$ flux in 2015 was 10,298,590.6 g/yr and in 2016 it was 4,692,206.2 $\mathrm{g} / \mathrm{yr}$. 
The total yearly $\mathrm{CO}_{2}$ flux in 2016 is $129,401,932.93 \mathrm{~g} / \mathrm{yr}\left(0.255 \mathrm{~g} / \mathrm{m}^{2} \mathrm{yr}\right)$ with a drainage basin of $508 \mathrm{~km}^{2}\left(5.08 \times 10^{8} \mathrm{~m}^{2}\right)$ (Knierim et al., 2015).

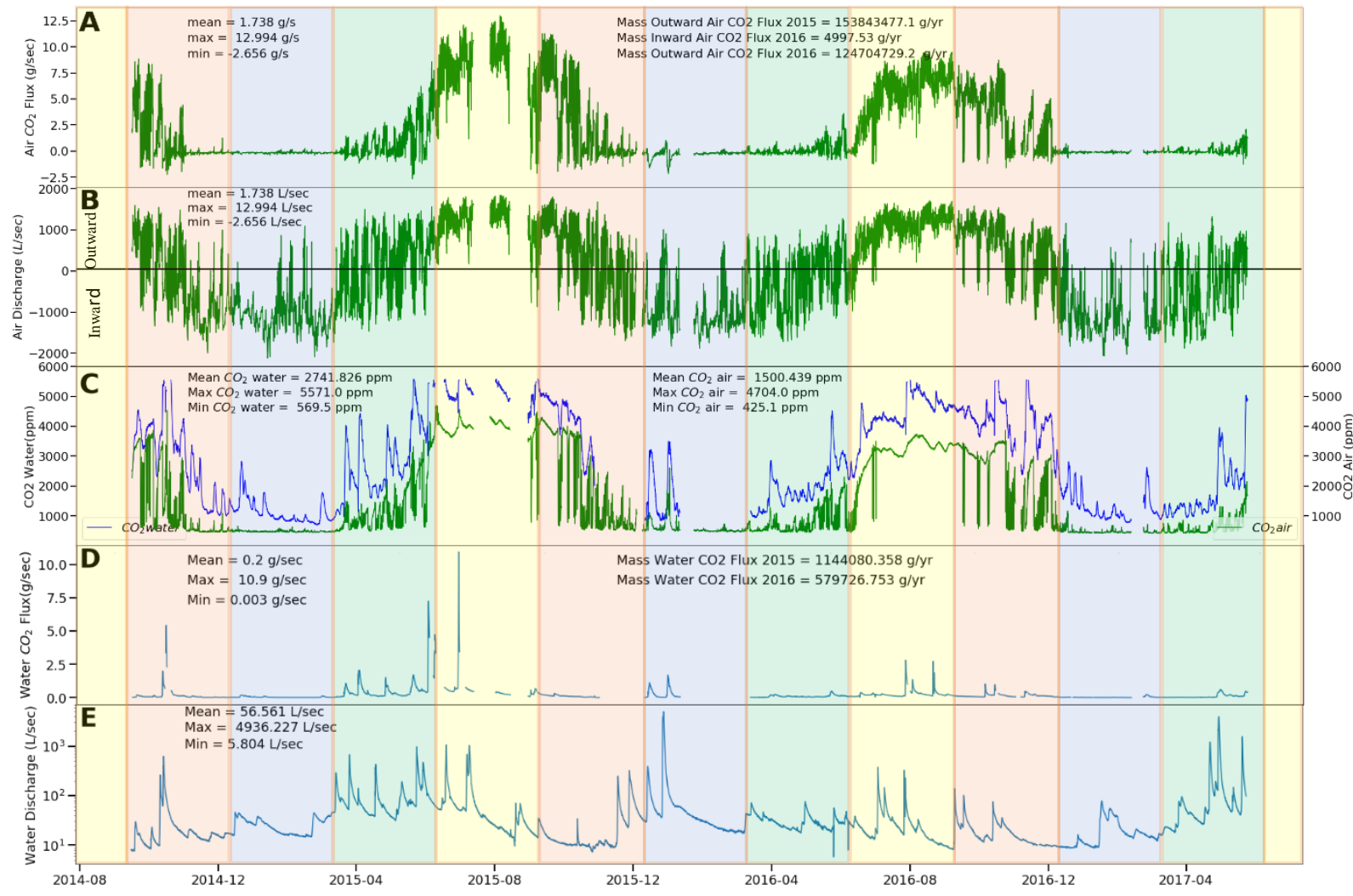

Figure 18: Time series plots of $\mathrm{CO}_{2}$ concentrations in the air and water, air $\mathrm{CO}_{2}$ flux, air discharge, water $\mathrm{CO}_{2}$ flux and water discharge. 
Air $\mathrm{CO}_{2}$ Flux

Four air discharge measurements were plotted against the wind velocity data measured at the date and time the spot measurements were collected. Cave air discharge was then estimated for the entire study period using a linear best-fit relationship between the wind velocity values and the estimated values of air discharge (Figure 19).

$$
Q_{\text {air }}=m V_{\text {air }}
$$

$Q_{\text {air }}$ is the total air discharge, $m$ is the calculated slope of 2.1 and $V_{\text {air }}$ is the continuous measured wind velocity data from the Campbell station. The continuous flux of $\mathrm{CO}_{2}$ in the air was calculated (Figure 18) using the $\mathrm{CO}_{2}$ concentration in atm and the continuous airflow discharge.

To determine what drives the $\mathrm{CO}_{2}$ flux, the $\mathrm{CO}_{2}$ flux was compared to air discharge and the $\mathrm{CO}_{2}$ concentration. To analyze the relationship between the air $\mathrm{CO}_{2}$ flux and discharge variables the two were plotted against each other in two separate plots, separating the airflow regimes (Figures $20 \& 21$ ). Figure 20 represents the positive (outward flow) regime. The data fans out from $(0,0)$ and stays relatively contained producing a pearson $r$ of 0.89 and a spearman $r$ of 0.9. To further investigate if changes in concentration effect the overall flux, a flux curve was placed on the plot using discharge data and average concentration. For the positive flow regime, the curve does not fit the data perfectly, as expected if the air $\mathrm{CO}_{2}$ concentration influences flux. Figure 20 represent the negative (inward flow) regime, fanning downward from $(0,0)$ but concentrated mostly where flux is closer to 0 and scatters below. The pearson $r$ value produced was 0.05 and the spearman $r$ was 0.23 . A flux curve was also compared to the negative portion of the data. The curve fits the uppermost portion of the plot but does not account for the scatter below. 
Alternatively, in Figure 22 air $\mathrm{CO}_{2}$ flux and the concentration were compared, showing they are very closely related, clearly linear despite a few scatter points in the negative flux region. The plot produced a pearson $\mathrm{r}$ of 0.90 and a spearman $\mathrm{r}$ of 0.68 , being higher than the correlation between flux and discharge. A flux curve using concentration and average discharge was compared to the plot. The result shows the line to fit the data closer than the previous plot but does not account for the scatter points below.

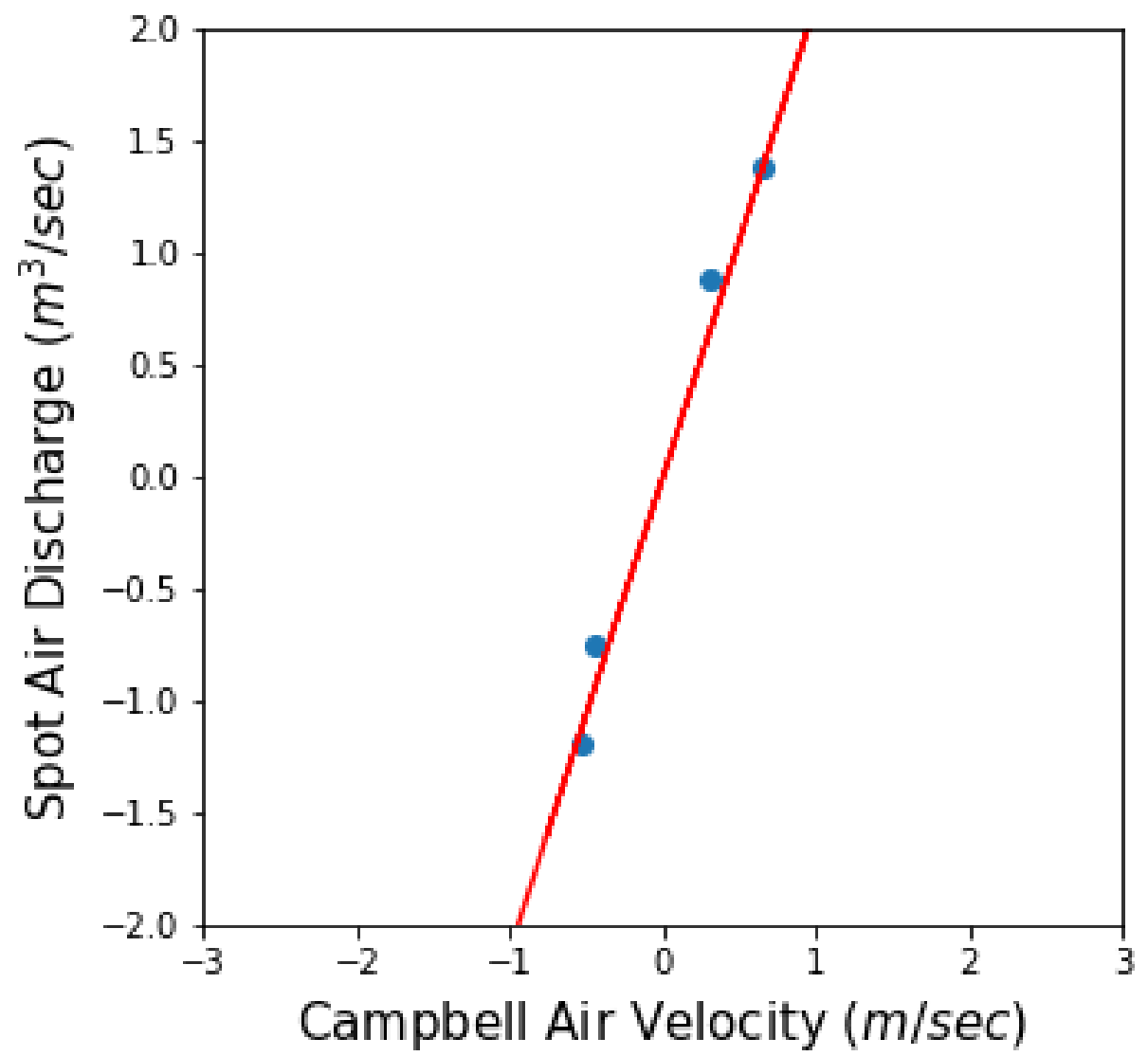

Figure 19: Measured spot velocity measurements across a cross section of the stream. Used calculated discharge and the station wind velocity measurements to create a linear best fit relationship to estimate air discharge over the time span of the study. 


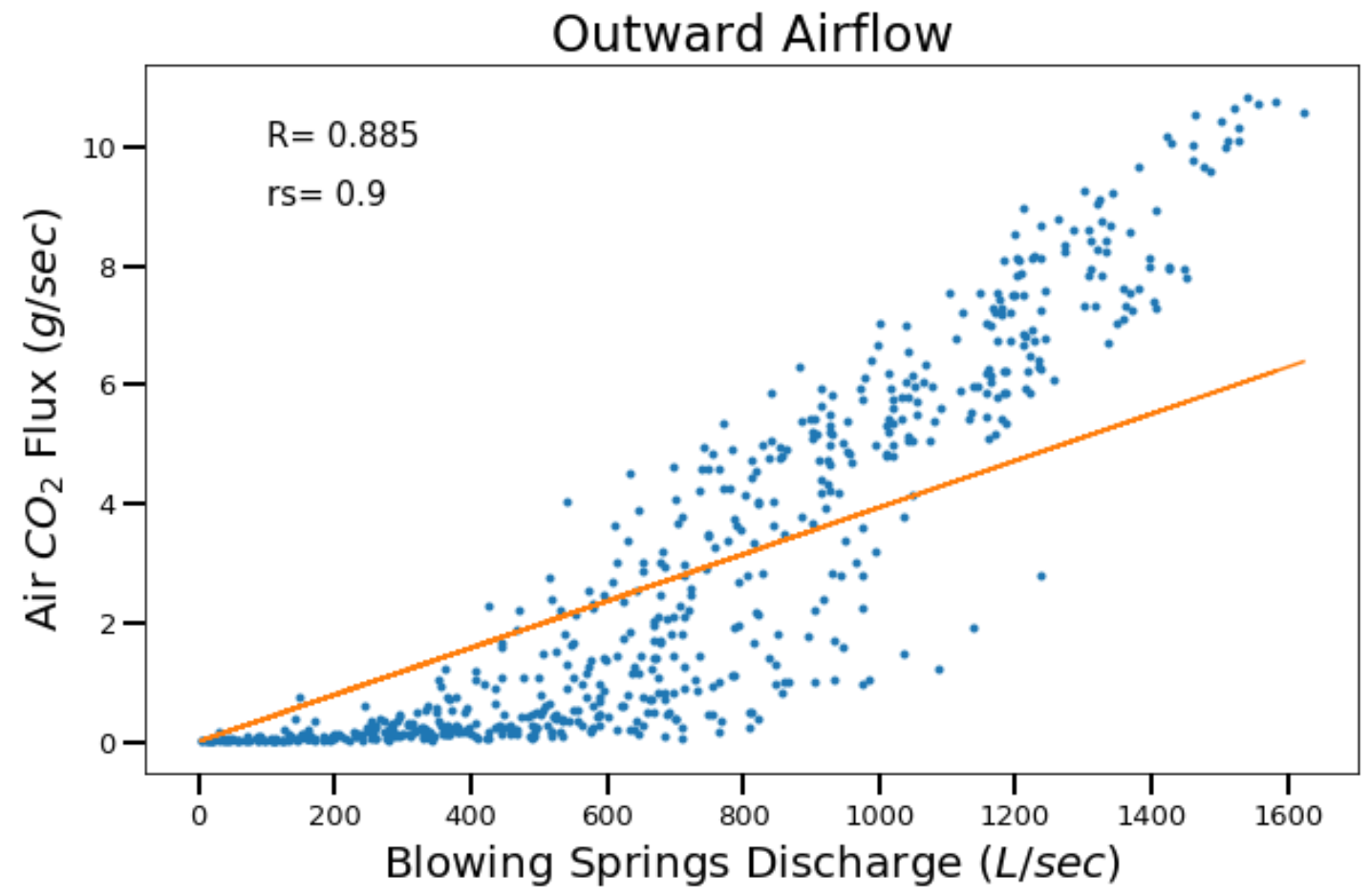

Figure 20: $\mathrm{CO}_{2}$ flux vs. air discharge during an outward airflow regime. Flux curve with fixed concentration compared. Pearson $R$ and Spearman $r$ correlation coefficient disnlaved.

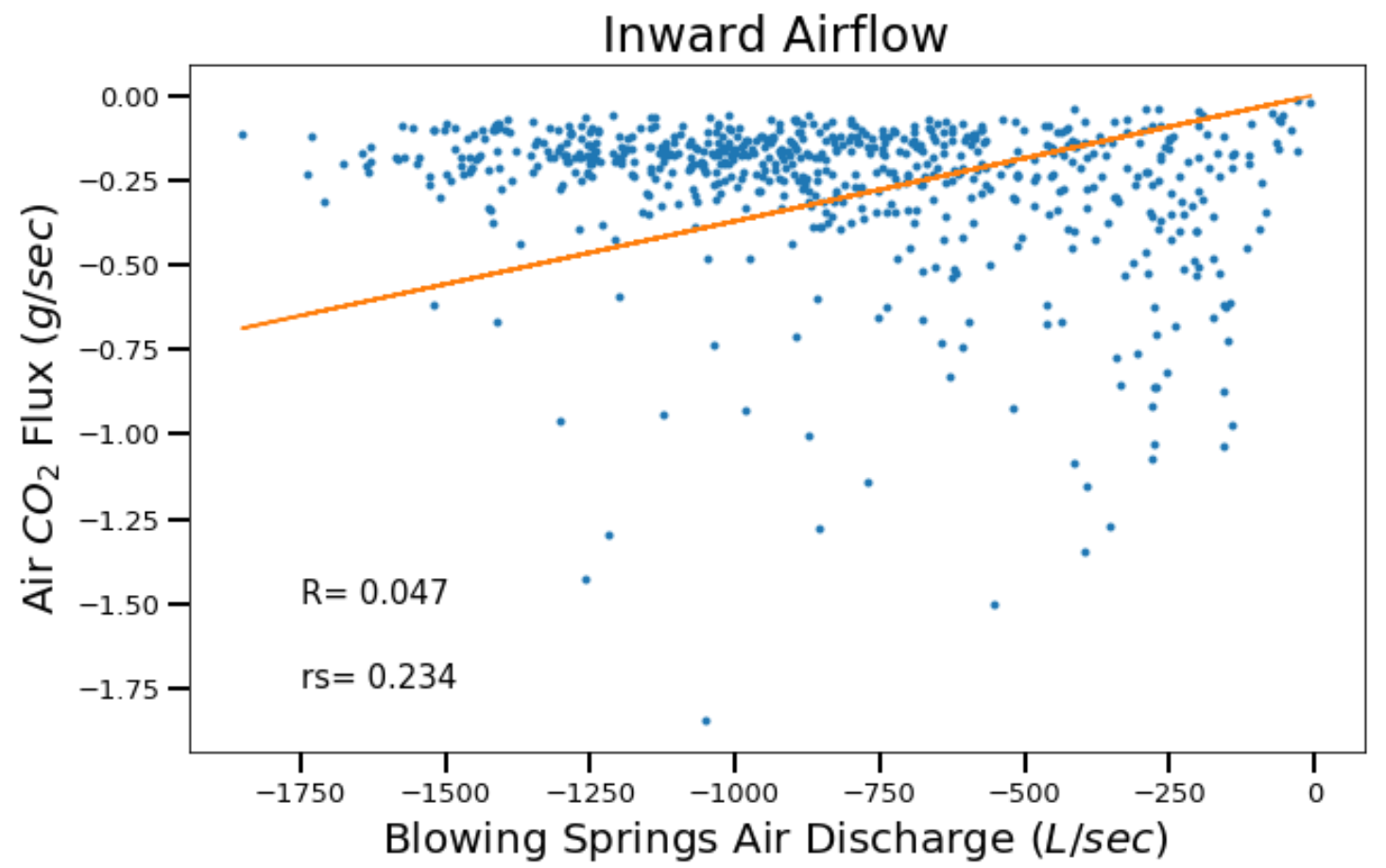

Figure 21: $\mathrm{CO}_{2}$ flux vs. air discharge during an inward airflow regime. Flux curve with fixed concentration compared. Pearson $R$ and Spearman r correlation coefficient displayed. 


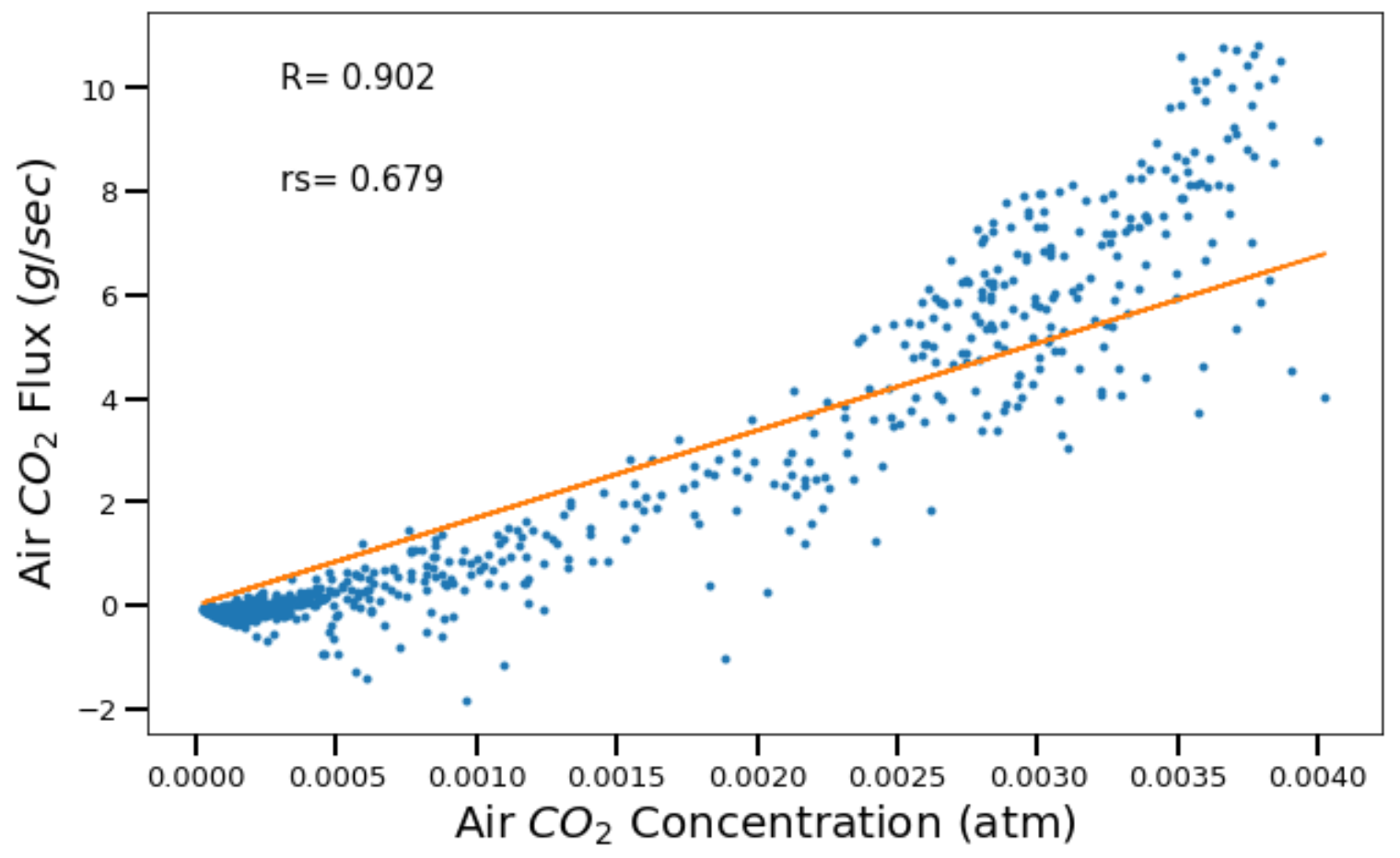

Figure 22: $\mathrm{CO}_{2}$ flux vs. air $\mathrm{CO}_{2}$ concentration. Flux curve with fixed discharge compared. Pearson $R$ and Spearman $r$ correlation coefficient displayed. 
Water $\mathrm{CO}_{2}$ Flux

To estimate the $\mathrm{CO}_{2}$ flux in the stream, the stream discharge from Little Sugar Creek USGS station (QLS) and applied a regression to estimate discharge at Blowing Springs (QBS) (Knierim et al., 2015):

$$
Q_{B S}=0.0066 Q_{L S}+0.0023, r^{2}=0.08, p<0.0001
$$

Using the above equation, Blowing Springs discharge was calculated over the study period. To calculate the $\mathrm{CO}_{2}$ flux was then calculated using equations 6 and 7.

To analyze the relationship between discharge and $\mathrm{CO}_{2}$ flux, Figure 23 shows a log plot of the two. The resulting relationship was directly proportional, portraying the $\mathrm{CO}_{2}$ water flux is directly dependent on stream discharge with a Pearson $r$ of 0.92 and a Spearman $r$ of 0.78 . A flux curve was compared to the plot using discharge and average concentration. The curve fits perfectly with the flux/discharge data.

Figure 24 shows another time series comparison, but between water $\mathrm{CO}_{2}$ concentration and water $\mathrm{CO}_{2}$ flux. The relationship between the two variables do not display a statistically significant correlation. To further test the relationship, Figure 24 shows the concentration and flux plotted against each other on a semi log plot. The plot is mainly scatter and confirms there is no statistically significant correlation between the two variables, producing a Pearson R of 0.35 and a Spearman $r$ of 0.78. A flux curve was compared to the plot using concentration and an average discharge. While the curve fits the data relatively well, the curve does not account for the scatter above the curve.

To understand the distribution of concentration and discharge in the air and water, figure 25 displays four histograms. Water discharge is set in log space, as it ranges multiple 
magnitudes, while the other histograms are linear. Air and water concentration and air discharge show bimodal distribution.

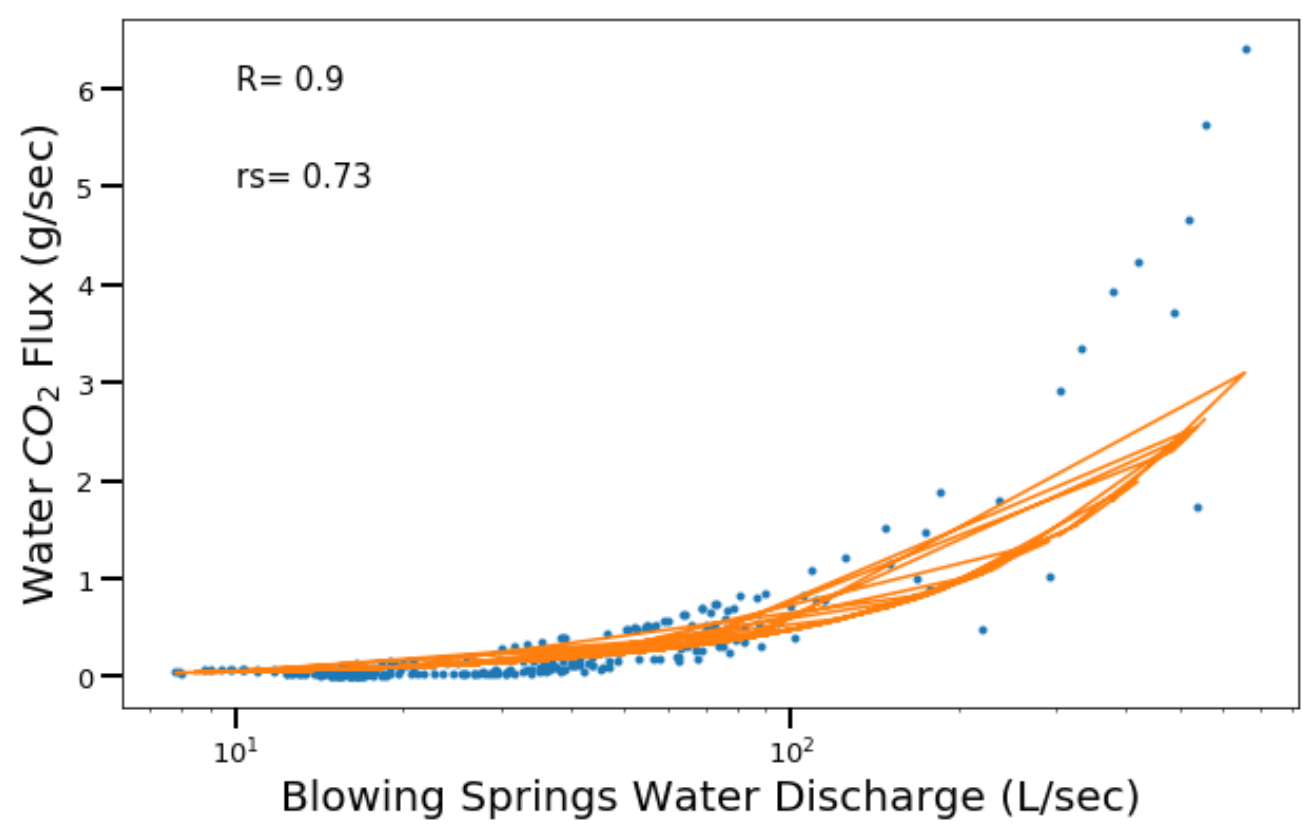

Figure 23: $\mathrm{CO}_{2}$ flux vs. water discharge. Flux curve with fixed concentration compared. Pearson $R$ and Spearman r correlation coefficient displayed.

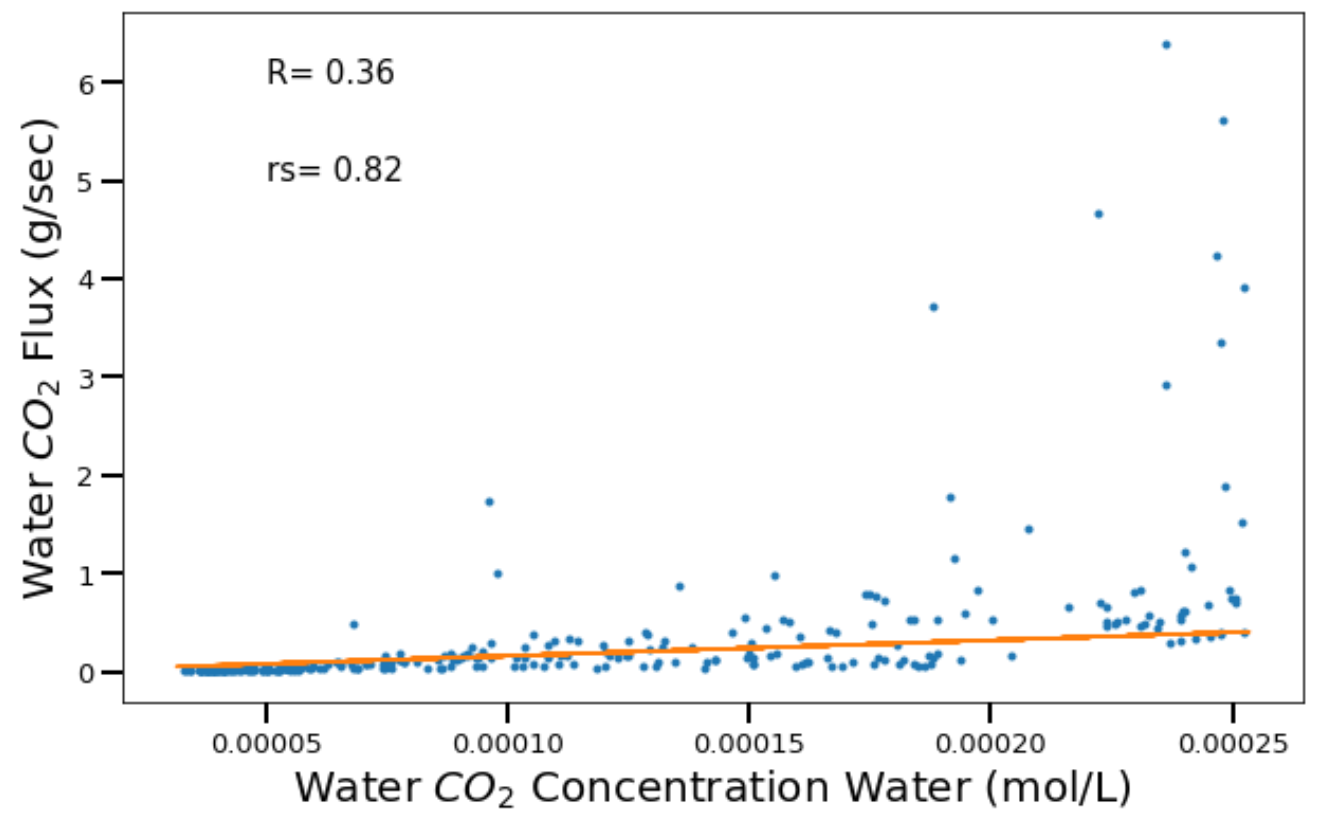

Figure 24: $\mathrm{CO}_{2}$ flux vs. water $\mathrm{CO}_{2}$ concentration. Flux curve with fixed discharge compared. Pearson $R$ and Spearman r correlation coefficient displayed. 

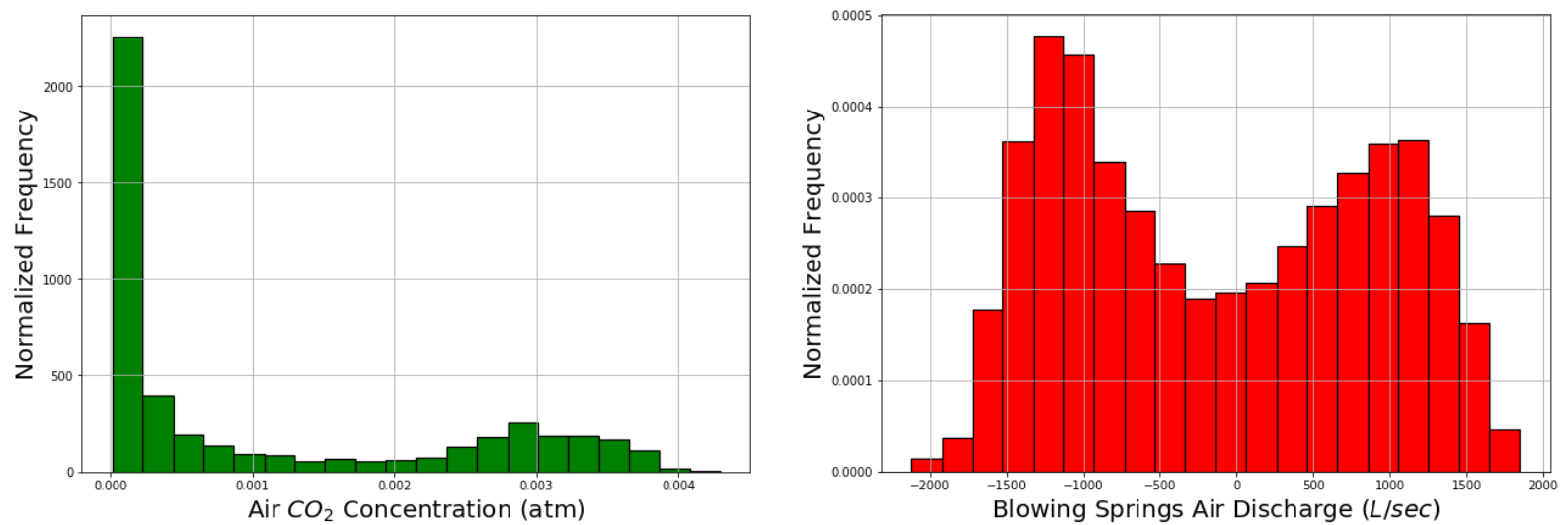

Figure 25: Histograms of $\mathrm{CO}_{2}$ concentration and discharge in the air and water.
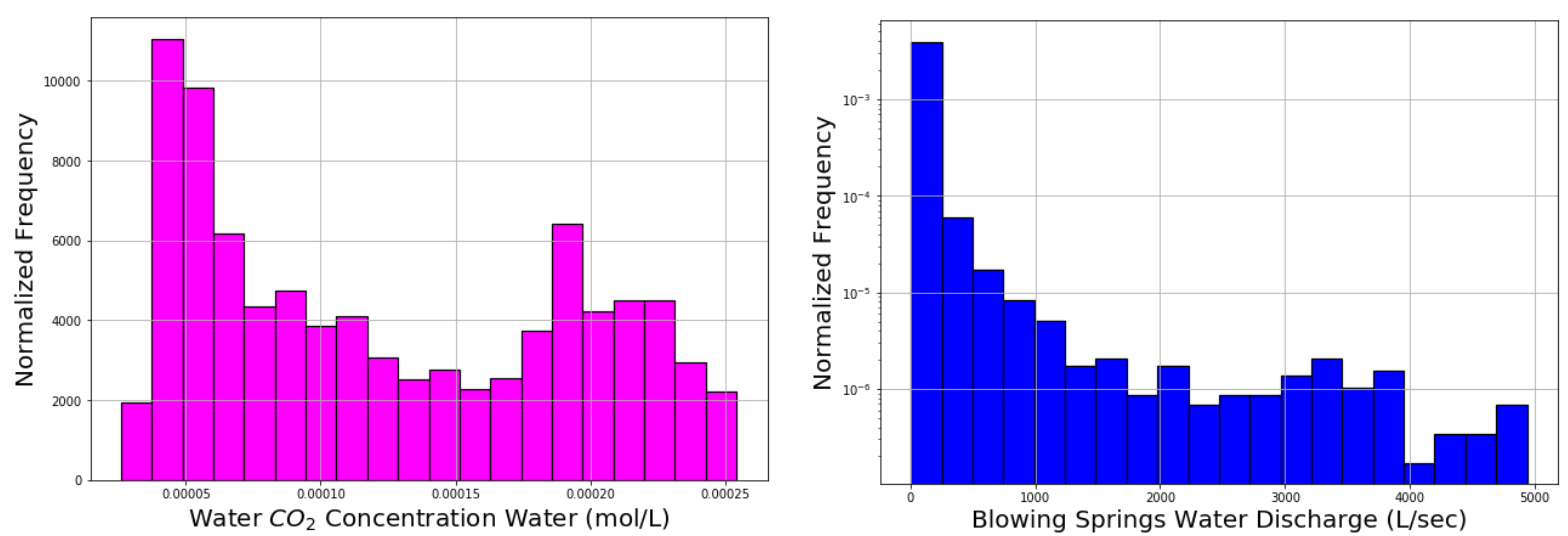


\section{DISCUSSION}

\section{The Chimney Effect}

The airflow within Blowing Springs Cave displays variations over seasonal cycles. Inward airflow is present in the winter, and outward airflow is present in the summer (Figure 6). The patterns observed in Blowing Springs Cave mirror those produced by the chimney effect (Covington \& Perne, 2015), which is the most common cave airflow mechanism. Many caves around the world experience this kind of airflow behavior.

This airflow pattern results from the interaction of cave air and surface air. For chimney effect ventilation to occur, lower and upper surface entrances must be present. Blowing Springs has a lower main entrance, which is the only entrance large enough for a human to fit into. The upper entrances are likely small holes and fractures that are too small for human entry.

As surface air temperatures rise and fall above and below the relatively constant cave air temperatures, density differences between the two air bodies drive flow direction and velocity. The chimney effect pattern is easily seen within the airflow velocity and temperature data from Blowing Springs Cave data. The cave airflow direction is strongly correlated to the temperature differences observed between Blowing Springs and the surface (Figure 6, 7, 8). When the air flows outward through the entrance, external temperatures are higher than cave temperatures. When wind direction flows inward, external temperatures are lower than cave temperatures. Airflow direction reversals occur diurnally during transitional periods seen in the fall and spring.

\section{$\mathrm{CO}_{2}$ Analysis}

The $\mathrm{CO}_{2}$ concentrations within Blowing Springs Cave display variations of an order of magnitude over seasonal cycles. In Figure 6 three different airflow regimes are shown. During 
winter, an inward wind direction regime was seen. As the surface air ventilates into the system, $\mathrm{CO}_{2}$ concentrations fall to minimum values, because surface air $\mathrm{CO}_{2}$ concentrations are lower than cave air $\mathrm{CO}_{2}$ concentrations. During the summer, an outward airflow regime is present. Airflow is directed from the upper zones in the soil and epikarst, through the cave passage, allowing the denser $\mathrm{CO}_{2}$ rich cave air to flow out the entrance. Because the air infiltrates down through zones of higher $\mathrm{CO}_{2}$ concentrations during warm periods, cave air $\mathrm{CO}_{2}$ concentrations during the summer reach a maximum.

During the fall and spring, diurnal temperature driven spikes and dips in $\mathrm{CO}_{2}$ are observed, as diurnal airflow reversals occur. Surface temperatures rise during the day, causing an outflux of cave air. $\mathrm{CO}_{2}$ spikes are seen during the day as temperatures rise. As surface temperatures fall at night, $\mathrm{CO}_{2}$ falls, resulting from an influx of external air. Even on a diurnal timescale $\mathrm{CO}_{2}$ concentrations in the air respond to the reversing airflow, resulting in highly varied concentrations.

Figure 10 compares the $\mathrm{CO}_{2}$ concentrations in the air and water and wind velocity within the same week in the fall. In the beginning of the week, the concentrations remain relatively high with short dips at night, then transition into consistently low concentrations with short peaks during the day. The high concentration period occurs while external temperature remains above the internal cave temperature, and transitions to low concentrations when external temperature drops below the cave temperature. During the high concentration period the concentration dips are rapid compared to somewhat slower peaks in the low concentration period. During periods where air is blowing into the cave, the transition is almost immediate, due to the high ventilation of external air rushing into the cave and relatively short distance from the station to the entrance, allowing little chance of gas exchange with the water. Reversals transitioning into air blowing 
outwards, produce a more gradual peak, as the air, having a relatively long flow path, gradually flows through the vadose zone and cave before reaching the sensor. This allows for mixing or gas exchange between the air and water. Even when temperatures drop or rise only a degree higher or lower than the cave temperature, the chimney effect will reverse the airflow.

Figures 6 shows that, during periods when external temperatures are constantly below or above the cave temperatures, as seen in the winter and summer, the patterns in $\mathrm{CO}_{2}$ and wind direction stay relatively stable. Moving towards the transitioning periods in the fall and spring, the patterns become noisy, as the temperatures diurnally rise and fall above and below the internal cave temperatures. Observing the periodic temperature density driven highs and lows in $\mathrm{CO}_{2}$ concentrations, it is apparent the chimney effect drives seasonal fluxes in gaseous $\mathrm{CO}_{2}$.

The seasonal trends of gaseous and dissolved $\mathrm{CO}_{2}$ follow a similar pattern, but concentrations in the air vary over short timescales, while the variability in the water is smoother (Figure 6). The sporadic nature of the air concentrations results from the almost immediate response from the changing airflow directions. Succeeding the immediate air concentration transition, water $\mathrm{CO}_{2}$ concentrations respond but are delayed (Figure 10). This results from the time that the water needs to equilibrate to the concentration transitions in the air.

Previous studies have deployed different ways in quantifying or understanding the gas exchange of $\mathrm{CO}_{2}$ within cave systems. In a study by Mattey et al. (2016), the flow of carbon by measuring the different chemical phases carbon takes within a cave in the air and water was modeled. The gas exchange between air and water can vary seasonally and by airflow reversal. The largest determinant of gas exchange is the difference in concentrations in the air and water. In this study, because there is continuous $\mathrm{CO}_{2}$ concentrations in the air and water, cross correlations were used to determine the lag time between $\mathrm{CO}_{2}$ concentrations in the air and 
water, to better understand the gas exchange between these two mediums. To distinguish the length of the lag during different reversals, cross correlations between the $\mathrm{CO}_{2}$ concentrations in the air and water were taken at different time intervals. Cross correlations functions were calculated for two time periods shown in Figures 11 and 12.

During the transitional seasons the cross correlations are the most meaningful as the air concentrations are constantly shifting, as reflected in the daily peaks in the cross correlation function as the water concentrations are constantly trying to equilibrate to changing concentrations in the air.

Cross correlations during periods of outward airflow, experienced higher correlation peak values than cross correlations during periods of inward airflow, transitional and stagnant. This outcome is understood to occur because of the location of the station and direction of the airflow relative to the stream. The location of the station is closer to the entrance than it is to the sump. During periods of outward airflow the air is flowing from the sump out the entrance, allowing a longer period of time for equilibration to occur before the flow reaches the station were data were recorded.

The gas exchange between air and water summer and winter time series are more independent of each other as air $\mathrm{CO}_{2}$ concentrations stay relatively stagnant for an extensive time period. This allows other components such as water discharge to influence concentration in the water.

$\mathrm{CO}_{2}$ Profile

$\mathrm{CO}_{2}$ variations occur longitudinally along the flow path seasonally. Because our station is placed in one location in the cave, most of our data analyzes temporal changes in $\mathrm{CO}_{2}$. The 
general trend shows $\mathrm{CO}_{2}$ concentrations gradually increasing from a low concentration at the entrance to a high concentration at the sump, or the back of the cave. During the winter this is expected as the sump is the farthest away from surface air circulation and surrounded by air and water that has been saturated by percolation through the vadose zone, while the entrance is constantly exposed to surface air or mixing of surface and cave air. During the summer it is expected that the water has the highest concentration at the sump, but not likewise in the air. Because the airflow is moving outwards with the flow of the stream, it may be expected that the concentration in the air to increase as it has the time for the gas exchange to occur as it flows towards the entrance. The fact that air concentrations decrease in the downstream direction in the summer indicates inflow of fresh air by infeeders connected to the surface along the flow path. This interpretation is supported by observations of low $\mathrm{CO}_{2}$ concentrations in the air of some infeeding passages (Knierim et al. 2015).

In correlation with the station data, summer shows the highest concentrations, winter shows the lowest concentrations, and fall sits between the other two seasons. Furthermore, concentrations in the water are always higher than the air.

Interestingly, during the fall and summer, both the air and water experience $\mathrm{CO}_{2}$ concentration spikes at the station, which is not seen in the winter. This could result from the length of time the sensor was equilibrating while increasing concentration from anthropogenic sources. Another possibility is that a small vent or infeeding stream, went unnoticed and increased the concentration of $\mathrm{CO}_{2}$ in the water.

Wanninkhof, 2009 describes flux, or exchange to be dependent on the differences in concentrations in the air and water to be a thermodynamic driving force. In addition to using cross correlation to examine exchange, the differences in water and air $\mathrm{CO}_{2}$ concentrations from 
the spot measurements taken along the stream was also examined. In the fall, there is a larger amount of exchange than in the winter and summer at all stations. This is due to the constant changes in the air $\mathrm{CO}_{2}$ concentrations seen in the transitional season, allowing larger differences in concentration between the air and water inside the cave, leading to higher amount of exchange. The low values in the winter in summer are due to the constant flow of air in one direction and small differences in concentrations in the air and water.

\section{$\mathrm{CO}_{2}$ Budget}

Two of the largest drivers of $\mathrm{CO}_{2}$ dynamics within caves are cave streams and airflow (Sánchez-Cañete et al., 2013). Determining mass $\mathrm{CO}_{2}$ flux quantifies how $\mathrm{CO}_{2}$ is entering and exiting the system, and by what influence. The two main pathways for $\mathrm{CO}_{2}$ gas to enter or exit

\section{$\mathrm{CO}_{2}$ Budget in}

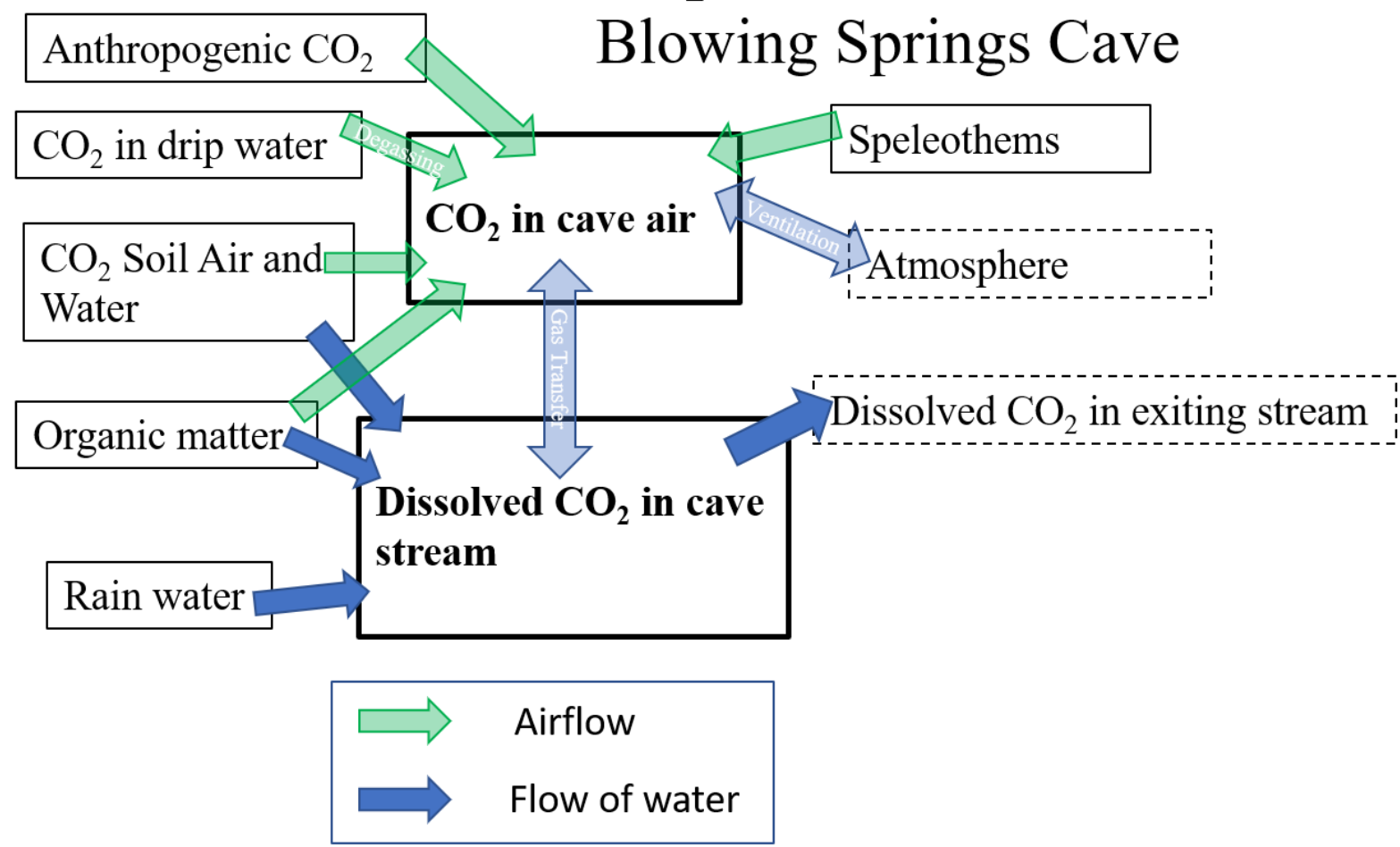

Figure 26: Conceptual $\mathrm{CO}_{2}$ budget for Blowing Springs Cave. 
the system are air-filled passage and the stream (Figure 26). In a study by Milanolo and Gabrosvek (2009), they calculated the spatial and temporal variability of $\mathrm{CO}_{2}$ flux in a cave with a temperature driven airflow regime. They calculated the flux using convective airflow rate and $\mathrm{CO}_{2}$ concentration of the inlet stream and the air (Milanolo and Gabrosvek, 2009). In our study, to examine the dominant control of the variations in dissolved and gaseous $\mathrm{CO}_{2}$ concentrations in Blowing Springs Cave (Figure 26), $\mathrm{CO}_{2}$ concentrations and discharge were compared with the $\mathrm{CO}_{2}$ flux in the air and water.

Air $\mathrm{CO}_{2}$ Flux

As expected, $\mathrm{CO}_{2}$ flux follows the same trend as the air discharge, resulting from the chimney effect binary airflow regime. To examine the two separate airflow regimes, discharge was split into two plots depicting each airflow regime (Figures 20 and 21). The positive flow regime returns a much higher correlation coefficient than the negative flow regime. When the two regimes are isolated, even though the negative flow regime is heavily concentrated on the top of the fan, the rest of the points are scattered downward within the range of the fan. The scatter below could be an error showing unrealistically low concentrations since it is expected for concentrations to remain constant with inward airflow. The positive regime airflow is relatively evenly concentrated throughout the length of the fan shape although with a larger distribution.

As $\mathrm{CO}_{2}$ flux is equal to the discharge multiplied by the concentration, the amount of influence the changes in concentration have on the overall flux was tested by comparing a flux curve to the air discharge/flux plot, accounting for the discharge and a fixed concentration $\left[\mathrm{CO}_{2}\right]_{\mathrm{avg}}$. If the flux curve fits the data perfectly, this means changes in concentration do not influence the overall flux. If it does not fit the data perfectly then changes in concentration do influence overall flux. 


$$
Q_{\mathrm{CO} 2}=\frac{Q_{\text {air }}\left[\mathrm{CO}_{2}\right]_{\text {avg }} M_{\mathrm{CO} 2}}{R T},
$$

Flux curves were compared to both the positive and negative flux vs. discharge plots. On the positive plot the flux curve fits the data directly in the middle, depicting during outward airflow changes in concentration are not as important as air discharge is to the overall flux. On the negative plot the flux curve fits the concentrated portion of the plot. This could either show that the scatter below is based on error or changes in concentration are more influential to the overall flux during inward flow than during in outward flow.

Variability in air $\mathrm{CO}_{2}$ concentration could also be driving changes in the $\mathrm{CO}_{2}$ flux in the air. The concentration also is a driving mechanism for air $\mathrm{CO}_{2}$ flux, as both follow a similar trend in their individual timeseries. To further investigate the correlation between the flux and the concentration, the two were plotted against each other. The plot is fairly linear, relatively clean on the top of the data and scatters below.

The flux curve needed to compare to the concentration vs flux plot uses concentration and a fixed discharge.

$$
Q_{\mathrm{CO} 2}=\frac{Q_{\text {avg }}\left[\mathrm{CO}_{2}\right]_{a} M_{\mathrm{CO} 2}}{R T},
$$

The flux curve fit the data well but did not account for the scatter below. Thus, discharge is still a influencing factor in mass air flux of $\mathrm{CO}_{2}$ but not as strong as concentration.

Clearly both $\mathrm{CO}_{2}$ concentration and air discharge have a strong influence on the air $\mathrm{CO}_{2}$ flux. The dominant factor allowing for both variables to have an influence over the flux is the low range of airflow compared to the concentration ranges. Since the airflow is not constantly flowing in the same direction, this allows for the concentration to play a dominant role. In Figure 
25, the histograms show air discharge compared to air concentration are not many orders of magnitude different. Also both air and water concentration and air discharge display bimodal distribution, indicative of the influence the two airflow regimes have on concentration. In Figures 20 and 21 most of the scatter occurs when flux is below zero, when the airflow is blowing inwards. When the airflow is blowing inwards discharge becomes the dominant influence on flux, but when there is an outward airflow present both discharge and concentration are coupled as both influences over flux.

The yearly mass flux of $\mathrm{CO}_{2}$ coming out of Blowing Springs in the air during outward airflow is calculated at $153843477.1 \mathrm{~g} / \mathrm{yr}$ in 2015 and $124704729.2 \mathrm{~g} / \mathrm{yr}$ in 2016. In a paper by Bourges et al. (2006), they quantify the yearly flux of $\mathrm{CO}_{2}$ leaving their cave system in France, Aven d'Orgnac. They use $\mathrm{CO}_{2}$ concentration time series data and profiles at multiple locations in the cave and entrances. They calculated a mean $\mathrm{CO}_{2}$ production of about 2 tons per day and an $\mathrm{CO}_{2}$ rich air exiting rate of around 60000 to $160000 \mathrm{~m}^{3} /$ day during the summer time. During the winter, airflow was entering the cave in large quantities. At Blowing Springs, mass air flux of $\mathrm{CO}_{2}$ during inward was roughly calculated using the winter $\mathrm{CO}_{2}$ concentration at BS07 from our spot measurements and the average discharge from the day the spot measurements were taken. The result was a mass flux of $4997.53 \mathrm{~g} / \mathrm{yr}$. Yearly total mass flux in 2016 from the air was calculated to be $124,709,726.7 \mathrm{~g} / \mathrm{yr}\left(.25 \mathrm{~g} / \mathrm{m}^{2} \mathrm{yr}\right)$. In Aven d'Orgnac cave, their total yearly carbon flux in the air was calculated to $343 \mathrm{~g} / \mathrm{m}^{2} \mathrm{yr}$ in a drainage area of $0.56 \mathrm{~km}^{2}$.

\section{Water $\mathrm{CO}_{2}$ Flux}

In contrast to the airflow within Blowing Springs, the stream continuously flows in one direction and contains a consistently higher concentration of $\mathrm{CO}_{2}$. Two main factors control the $\mathrm{CO}_{2}$ flux in the water, concentration and water discharge. 
On both the time series plots of mass flux and discharge, mass flux appears to be almost identical to the discharge, following a trend of a hydrograph. The data in Figure 23 of discharge and mass flux follow a linear trend in log space. The data exhibit relatively little scatter at high discharge, and somewhat more scatter at low discharge. It is evident the water discharge is the main driving mechanism controlling $\mathrm{CO}_{2}$ mass flux in the water but is not as important of a control during low flow period.

The flux curve tests the amount of influence changes in concentration have on flux by using water discharge and an average concentration.

$$
Q_{\mathrm{CO} 2}=Q_{\text {Stream }}\left[\mathrm{CO}_{2}\right]_{\mathrm{avg}} M_{\mathrm{CO} 2},
$$

The curve fits the data very well. The comparison represents the lack of influence changes in concentration have on the overall water $\mathrm{CO}_{2}$ flux.

Looking at both time series of mass flux and $\mathrm{CO}_{2}$ concentrations, comparing mass flux and water concentrations show very little correlation. Spikes in both the concentration and mass flux trend together (Figures 18). Concentration appears to be lightly correlated, but not enough to drive mass flux values. To further investigate the extent of their correlation, a semi log plot was produced of concentration and mass flux (Figure 24). The data shows scatter with some correlation, proven with the extremely low correlation coefficient.

The flux curve represents the concentration and average discharge.

$$
Q_{\mathrm{CO} 2}=Q_{\mathrm{avg}}\left[\mathrm{CO}_{2}\right]_{w} M_{\mathrm{CO} 2},
$$

The curve fits the data well but does not account for the scatter above of a magnitude of one thousand. Represented by these curves, water discharge clearly has the greater effect on water $\mathrm{CO}_{2}$ flux. 
Fluctuations in water discharge primarily control flux. Unlike the airflow, the cave stream is always flowing in one direction at a relatively fast pace. Water discharge and flux vary over multiple orders of magnitude, whereas concentration does not. Because the water is moving through the system so rapidly, this allows discharge to play a dominant role in water $\mathrm{CO}_{2}$ flux while obstructing the amount of influence concentration can have on flux. In Figure 25, the histograms show water discharge compared to water concentration are many orders of magnitude different.

The yearly mass flux of dissolved $\mathrm{CO}_{2}$ is calculated at $10,298,590.6 \mathrm{~g} / \mathrm{yr}\left(0.02 \mathrm{~g} / \mathrm{m}^{2} \mathrm{yr}\right)$ in 2015 and 4,692,206.2 $\mathrm{g} / \mathrm{yr}\left(0.009 \mathrm{~g} / \mathrm{m}^{2} \mathrm{yr}\right)$ in 2016. In a study by Yan et al. (2011) in the Houzhai Basin, southwest China, they quantify the carbon uptake rate of $\mathrm{CO}_{2}$ in karst streams. Their yearly rate was $20.7 \mathrm{~g} / \mathrm{m}^{2} \mathrm{yr}$ with a drainage basin of $80.65 \mathrm{~km}^{2}$.

\section{Total $\mathrm{CO}_{2}$ flux}

Quantifying the $\mathrm{CO}_{2}$ flux exiting a cave system brings us one step closer to understanding the influence caves have on the overall carbon budget. The yearly total mass $\mathrm{CO}_{2}$ flux was calculated at $129,401,932.93 \mathrm{~g} / \mathrm{yr}\left(0.255 \mathrm{~g} \mathrm{C} / \mathrm{m}^{2} \mathrm{yr}\right)$ with a drainage basin of $508 \mathrm{~km}^{2}\left(5.08 \times 10^{8}\right.$ $\mathrm{m}^{2}$ ) (Knierim et al., 2015). Ohtsuka et al. (2007), examine the soil fluxes in a temperate deciduous forest in central Japan. The location in Japan produces a mean estimated annual soil $\mathrm{CO}_{2}$ flux of $710 \pm 44 \mathrm{~g} \mathrm{C} / \mathrm{m}^{2} \mathrm{yr}$ on 1 ha of land. Li et. al (2012) examined carbon pools in the Missouri Ozarks in the non-harvested forests of The Missouri Ozark Forest Ecosystem Project (MOFEP). Annual soil respiration rates in the Missouri Ozarks $1787 \mathrm{~g} \mathrm{C} / \mathrm{m}^{2} \mathrm{yr}$ over about 4 ha of land. Soil fluxes in temperate deciduous forests compared to carbon fluxes flowing through Blowing Springs Cave are 2 or 3 orders of magnitude larger. The emissions of carbon by caves using Blowing Springs Cave as an example shows karst contributes to the global carbon cycle by 
only a minimal portion. By comparing the $\mathrm{CO}_{2}$ flux against other soil fluxes, the Blowing Springs mass flux is put into perspective of the contribution to the carbon cycle caves are producing. 


\section{CONCLUSION}

Chimney effect airflow is the dominant mechanism controlling $\mathrm{CO}_{2}$ variations seasonally and diurnally at Blowing Springs Cave. The variations of $\mathrm{CO}_{2}$ between the summer and winter result in a difference of an order of magnitude. During the colder months, surface air is ventilated throughout the cave system, bringing lower concentrations of $\mathrm{CO}_{2}$ through the passage. Since high ventilation consistently occurs when external temperatures remain below the internal cave temperature, both gaseous and dissolved $\mathrm{CO}_{2}$ concentrations remain at a minimum value.

As the external temperatures approach consistently warm temperatures, the airflow reverses. Air is being pulled from the soil, phreatic and upper vadose zone, down through the cave passage and out the entrance. Due to the source of higher $\mathrm{CO}_{2}$ values being pulled into the cave passage, $\mathrm{CO}_{2}$ concentrations remain at a maximum, of an order of magnitude higher than the values seen in the winter months. Because this airflow regime takes longer to reverse into, the response in the $\mathrm{CO}_{2}$ concentrations are slightly delayed.

In transitional seasons (fall and spring), diurnal reversals occur as the external temperatures rise and fall above and below the internal temperature during the day and night. The sensitivity in the airflow reversal response of only a few degrees, and the quick response in the $\mathrm{CO}_{2}$ concentration, proves the dominance of the chimney effect.

$\mathrm{CO}_{2}$ concentrations in the water respond to changes in concentrations in the air, diurnally and seasonally. The concentrations in the water experience a lag in the air concentrations. The length of the lag and value of correlation can vary depending on the type of airflow reversal that is occurring. 
$\mathrm{CO}_{2}$ concentrations vary longitudinally along cave stream as well as seasonally.

Typically, concentrations experience minimum values at the entrance, as it is constantly touching surface air, and gradually increase towards the back of the cave, where higher concentrations are being introduced by the soil and the sump.

Modelling the $\mathrm{CO}_{2}$ budget within the cave, creates an understanding of how the $\mathrm{CO}_{2}$ is being introduced, what the driving mechanism is, and how the $\mathrm{CO}_{2}$ is leaving the system. Within Blowing Springs Cave the main two mediums of $\mathrm{CO}_{2}$ transport are through the air-filled passage and the stream.

Changes in the $\mathrm{CO}_{2}$ flux in the air are driven by both changes in the air discharge and the $\mathrm{CO}_{2}$ concentration. The air discharge changes result from the chimney effect airflow reversals present in the cave, driving the influx and outflux of $\mathrm{CO}_{2}$ in the air. The concentration of $\mathrm{CO}_{2}$ also strongly drives the $\mathrm{CO}_{2}$ flux. Because the airflow is constantly shifting instead of flowing in one direction and the discharge is not multiple orders of magnitude larger than concentration, changes in concentration have a strong influence over flux.

Variability in the water discharge is the primary driving mechanism of variability in the mass flux of dissolved $\mathrm{CO}_{2}$. Compared to the changing flow directions in the air, the cave stream naturally flows in one direction, at a rapid pace. Thus, driving the flux of dissolved $\mathrm{CO}_{2}$.

By quantifying the $\mathrm{CO}_{2}$ budget in Blowing Springs and comparing it to soil fluxes and cave $\mathrm{CO}_{2}$ fluxes around the world in similar climates, it explains how much $\mathrm{CO}_{2}$ is routed through karst systems rather than emerging as soil $\mathrm{CO}_{2}$ flux. Blowing Springs emits two to three magnitudes smaller total mass $\mathrm{CO}_{2}$ flux than soil fluxes in areas in temperate deciduous forests. 
The dynamics of $\mathrm{CO}_{2}$ control speleogenesis by dissolution and precipitation of limestone. It is important to understand the mechanisms that drive the $\mathrm{CO}_{2}$ variations. Observing these mechanisms on a daily to yearly scale, can help extrapolate the results over time and understand the large-scale effects these mechanisms, such as airflow, have on the large-scale evolution of caves as well as understanding karst influence on the global carbon budget. 


\section{REFERENCES}

Adamski, J.C., Petersen, J.C., Freiwald, D.A., and Davis, J.V., 1995, Environmental and hydrologic setting of the Ozark Plateaus study unit, Arkansas, Kansas, Missouri, and Oklahoma: U.S. Geological Survey Water-Resources Investigations Report 94-4022, 76 p., accessed April 2, 2014, at http://pubs.usgs.gov/wri/wri944022/.

Atkinson, T.C., 1977, Carbon Dioxide in the Atmosphere of the Unsaturated Zone: An Important Control of Groundwater Hardness in Limestones: Journal of Hydrology, v. 35, p. 111123.

Baldini JUL, McDermott F, Clipson N (2006b) Effects of high-frequency cave atmosphere $\mathrm{pCO}_{2}$ variability on stalagmite climate proxy records. Geochim Cosmochim Acta 70:A30.doi:10.1016/j.gca.2006.06.169

Bourges, F., et al. "Microclimates of l'Aven d'Orgnac and Other French Limestone Caves (Chauvet, Esparros, Marsoulas)." International Journal of Climatology, vol. 26, no. 12, 2006, pp. 1651-1670.

Brahana, J.V., Tennyson, R., Terry, J., Hays, P.D., and Pollock, E.D., 2009, Reactivated basement faulting as a hydrogeologic control of hypogene speleogenesis in the southern Ozarks of Arkansas, USA, in Stafford, K., ed., Advances in hypogene studies: National Cave and Karst Research Institute Symposium 1-National Cave and Karst Research Institute, p. 99-110, at http://www.karstportal.org/ sites/karstportal.org/files/Symposium_0609_full.pdf.

Breecker, D.O., Payne, A.E., Quade, J., Banner, J.L., Ball, C.E., Meyer, K.W., and Cowan, B.D., 2012, The sources and sinks of $\mathrm{CO}_{2}$ in caves under mixed woodland and grassland vegetation: Geochimica et Cosmochimica Acta, v. 96, p. 230-246, doi:10.1016/j.gca.2012.08.023.

Cigna, Arrigo. "An Analytical Study of Air Circulation in Caves." International Journal of Speleology, vol. 3, no. 1/2, 1968, pp. 41-54. 
Covington, MD, M. Prelovsek, and F. Gabrovsek. "Influence of CO2 Dynamics on the Longitudinal Variation of Incision Rates in Soluble Bedrock Channels: Feedback Mechanisms." Geomorphology, vol. 186, 2013, pp. 85-95.

Covington, Matthew; "The importance of advection for $\mathrm{CO}_{2}$ dynamics in the karst 2 Critical Zone: an approach from dimensional analysis". (2015)

Covington, Matthew D., and Matija Perne. "consider a Cylindrical Cave: A Physicist's View of Cave and Karst science/vzemimo Valjasto Jamo: Pogled Fizika Na Znanost o Jamah in Krasu." Acta Carsologica, vol. 44, no. 3, 2015, pp. 363.

Cowan, B.D.; Osborne, M.C.; Banner, J.L.;- Temporal variability of cave-air $\mathrm{CO}_{2}$ in central Texas. Journal of Cave and Karst Studies, v. 75, no. 1, p. 38-50. DOI: 10.4311/2011ES0246

Dreybrodt, Wolfgang. "Chemical Kinetics, Speleothem Growth and Climate." Boreas, vol. 28, no. 3, 1999, pp. 347-356.

Dreybrodt, Wolfgang. "Principles of Early Development of Karst Conduits Under Natural and Man-Made Conditions Revealed by Mathematical Analysis of Numerical Models." Water Resources Research, vol. 32, no. 9, 1996, pp. 2923-2935.

Gulley J., Martin J., and Moore P. (2014), Vadose $\mathrm{CO}_{2}$ gas drives dissolution at water tables in eogenetic karst aquifers more than mixing dissolution, Earth Surf. Process. Landforms, 39, pages 1833-1846, doi: 10.1002/esp.3571

Hays, P.D., Knierim, K.J., Breaker, Brian, Westerman, D.A., and Clark, B.R., 2016, Hydrogeology and hydrologic conditions of the Ozark Plateaus aquifer system: U.S. Geological Survey Scientific Investigations Report 2016-5137, 61 p., http://dx.doi.org/10.3133/sir20165137.

Holcomb, Ginny S. Temporal $\mathrm{CO}_{2}$ Variations and the Influence of Bat Colonies in Speleogenesis: Continuous $\mathrm{CO}_{2}$ Monitoring in War Eagle Cavern, Arkansas, ScholarWorks@UARK, 2016. 
Houillon, N., et al. "Assessing Cave Internal Aerology in Understanding Carbon Dioxide (CO2) Dynamics: Implications on Calcite Mass Variation on the Wall of Lascaux Cave (France)." Environmental Earth Sciences, vol. 76, no. 4, 2017, pp. 1-19.

Jähne and Haußecker, 1998 B. Jähne, H. Haußecker Air-water gas exchange

Annual Review of Fluid Mechanics, 30 (1998), pp. 443-468

Johnson, M. S., Billett, M. F., Dinsmore, K. J., Wallin, M., Dyson, K. E. and Jassal, R. S. (2010), Direct and continuous measurement of dissolved carbon dioxide in freshwater aquatic systems—-method and applications. Ecohydrol., 3: 68-78. doi:10.1002/eco.95

Knierim, Katherine J., 1985. Stable Isotopes as a Tool to Characterize Carbon Cycling and Develop Hydrologic Budgets in Mantled Karst Settings. University of Arkansas, Fayetteville, Fayetteville, Arkansas, 2015.

Knierim, Katherine J., Phillip D. Hays, and Darrell Bowman. "Quantifying the Variability in Escherichia Coli (E. Coli) Throughout Storm Events at a Karst Spring in Northwestern Arkansas, United States." Environmental Earth Sciences, vol. 74, no. 6, 2015, pp. 46074623.

Lang M., Faimon J. and Ek C., 2015. The relationship between carbon dioxide concentration and visitor numbers in the homothermic zone of the Balcarka Cave (Moravian Karst) during a period of limited ventilation. International Journal of Speleology, 44 (2), 167-176. Tampa, FL (USA) ISSN 0392-6672 http://dx.doi.org/10.5038/1827-806X.44.2.6

Li, QL, JQ Chen, and DL Moorhead. "Respiratory Carbon Losses in a Managed Oak Forest Ecosystem." Forest Ecology and Management, vol. 279, 2012, pp. 1-10.

Mattey, D. P., et al. "Carbon Dioxide, Ground Air and Carbon Cycling in Gibraltar Karst."Geochimica Et Cosmochimica Acta, vol. 184, 2016, pp. 88-113.

Milanolo, S., and Gabrovšek, F., 2009, Analysis of Carbon Dioxide Variations in the Atmosphere of Srednja Bijambarska Cave, Bosnia and Herzegovina: Boundary-Layer Meteorology, v. 131, no. 3, p. 479-493, doi: 10.1007/s10546-009-9375-5. 
Ohtsuka, Toshiyuki, et al. "Biometric Based Carbon Flux Measurements and Net Ecosystem Production (NEP) in a Temperate Deciduous Broad-Leaved Forest Beneath a Flux Tower."Ecosystems, vol. 10, no. 2, 2007, pp. 324-334.

Pla, Concepcion, et al. "Assessment of $\mathrm{CO}_{2}$ Dynamics in Subsurface Atmospheres using the Wavelet Approach: From cavity-atmosphere Exchange to Anthropogenic Impacts in Rull Cave (Vall d'Ebo, Spain)." Environmental Earth Sciences, vol. 75, no. 5, 2016, pp. 1-16.

$\mathrm{Pu}$, Junbing, et al. "Hydrochemical and $\mathrm{PCO}_{2}$ Variations of a Cave Stream in a Subtropical Karst Area, Chongqing, SW China: Piston Effects, Dilution Effects, Soil CO2 and Buffer Effects." Environmental Earth Sciences, vol. 71, no. 9, 2014, pp. 4039-4049.

Sánchez-Cañete, Enrique P., et al. "Cave Ventilation is Influenced by Variations in the $\mathrm{CO}_{2}$ Dependent Virtual Temperature." International Journal of Speleology, vol. 42, no. 1, 2013, pp. 1.

Spo"tl C., Fairchild I. J. and Tooth A. F. (2005) Cave-air control on dripwater geochemistry, Obir Caves (Austria): Implications for speleothem deposition in dynamically ventilated caves. Geochim. Cosmochim. Acta 69, 2451-2468.

Tennyson, Rodney, Terry, J., Brahana, J.V., Hays, P.D., and Pollock, E.D., 2008, Tectonic control of hypogene speleogenesis in the southern Ozarks - Implications for NAWQA and beyond: U.S. Geological Survey Scientific Investigations Report 2008-5023, 37-46 p., accessed September 24, 2015, at http://pubs.usgs.gov/ sir/2008/5023/09tennyson.htm.

Vaughn, Kiefer A. Controls on Dissolution Rate Variation at a Pair of Underflow-Overflow Springs at the Savoy Experimental Watershed, ScholarWorks@UARK, 2015.

Wanninkhof et al., 2009 R. Wanninkhof, W.E. Asher, D.T. Ho, C. Sweeney, W.R. McGillis Advances in quantifying air-sea gas exchange and environmental forcing Annual Review of Marine Science, 1 (2009), pp. 213-244

Weary, D.J., and Doctor, D.H., 2014, Karst in the United States-A digital map compilation and database: U.S. Geological Survey Open-File Report 2014-1156, 27 p., accessed August 9, 2014, at http://pubs.usgs.gov/ of/2014/1156/. 
Wigley T.M.L. and Brown M.C (1976) The Physics of Caves. In The Science of Speleology (eds. T. D. Ford and C. H. D. Cullingford), pp. 329-358. London, Academic Press.

Yan, Junhua, et al. "Carbon Uptake by Karsts in the Houzhai Basin, Southwest China." Journal of Geophysical Research, vol. 116, no. G4, 2011. 